\title{
Decomposing Mean Sea Level Rise in a Semi-Enclosed Basin, the Baltic Sea
}

\author{
UlF GRÄWE AND KNUT KLINGBEIL \\ Leibniz Institute for Baltic Sea Research, Rostock, Germany \\ JESSICA KELLN AND SÖNKE DANGENDORF \\ University of Siegen, Siegen, Germany
}

(Manuscript received 28 March 2018, in final form 25 February 2019)

\begin{abstract}
We analyzed changes in mean sea level (MSL) for the period 1950-2015 using a regional ocean model for the Baltic Sea. Sensitivity experiments allowed us to separate external from local drivers and to investigate individual forcing agents triggering basin-internal spatial variations. The model reveals a basin-average MSL rise (MSLR) of $2.08 \pm 0.49 \mathrm{~mm} \mathrm{yr}^{-1}$, a value that is slightly larger than the simultaneous global average of $1.63 \pm 0.32 \mathrm{~mm} \mathrm{yr}^{-1}$. This MSLR is, however, spatially highly nonuniform with lower than average increases in the southwestern part $\left(1.71 \pm 0.51 \mathrm{~mm} \mathrm{yr}^{-1}\right)$ and higher than average rates in the northeastern parts $\left(2.34 \pm 1.05 \mathrm{~mm} \mathrm{yr}^{-1}\right)$. While $75 \%$ of the basin-average MSL externally enters the Baltic basin as a mass signal from the adjacent North Sea, intensified westerly winds and a poleward shift of low pressure systems explain the majority of the spatial variations in the rates. Minor contributions stem from local changes in baroclinicity leading to a basin-internal redistribution of water masses. An observed increase in local ocean temperature further adds to the total basinwide MSLR through thermal expansion but has little effect on the spatial pattern. To test the robustness of these results, we further assessed the sensitivity to six different atmospheric surface forcing reanalysis products over their common period from 1980 to 2005. The ensemble runs indicated that there are significant differences between individual ensemble members increasing the total trend uncertainty for the basin average by $0.22 \mathrm{~mm} \mathrm{yr}^{-1}$ ( $95 \%$ confidence intervals). Locally the uncertainty varies from $0.05 \mathrm{~mm} \mathrm{yr}^{-1}$ in the central part to up to $0.4 \mathrm{~mm} \mathrm{yr}^{-1}$ along the coasts.
\end{abstract}

\section{Introduction}

Mean sea level (MSL) rise in the world's oceans is mainly caused by thermal expansion of the water column due to warming and by freshwater input from melting glaciers and ice sheets (Cazenave and Llovel 2010; Dangendorf et al. 2017). Recent estimates of global MSL rise (MSLR) range from 1.3 to $2 \mathrm{~mm} \mathrm{yr}^{-1}$ since 1900 (Church et al. 2004; Hay et al. 2015; Dangendorf et al. 2017) and point toward a significant acceleration over the last three decades (Cazenave et al. 2018). However, at a regional scale, the knowledge of global MSLR is of limited use, as large deviations from the global mean can occur (Church et al. 2008). Such deviations may, for example, result from regional differences in ocean temperature and salinity changes and corresponding differences in ocean thermohaline expansion/contraction (e.g., Church

Corresponding author: Ulf Gräwe, ulf.graewe@io-warnemuende.de et al. 2008), changes in ocean circulation (Yin et al. 2010), and atmospheric forcing (e.g., Marcos and Tsimplis 2007). Especially at multidecadal to centennial time scales gravitational changes, following mass changes between the land and the ocean, induce significant regional sea level patterns, also known as fingerprints. These fingerprints can lead to $30 \%$ larger than global sea level changes in the far field and a relative sea level fall in the direct surroundings of the freshwater source (Mitrovica et al. 2001). Accompanied by the change in ice mass or any other source of terrestrial waters, Earth's crust rebounds on large spatial scales inducing deviations between relative and absolute MSLR (Riva et al. 2017). On interglacial time scales, this process is known as glacial isostatic adjustment (GIA; Peltier 2004) and has an ongoing and nearly linear influence on local twentiethcentury MSLR.

This large spatial MSLR variability demands local and regional sea level studies improving our understanding of involved processes ultimately supporting local coastal 
strategies. The Northern European Shelf, including the Baltic proper, is of particular interest as it is directly located in the vicinity of the Scandinavian forebulge region, thus showing one of the largest GIA signals in relative MSL worldwide (Peltier 2004). The GIA pattern ranges from strong uplift in the Gulf of Bothnia $\left(12 \mathrm{~mm} \mathrm{yr}^{-1}\right)$ over neutral values along the German North Sea and Baltic Sea coasts to significant subsidence rates along the Dutch, UK, and French coastlines (from -1 to $-2 \mathrm{~mm} \mathrm{yr}^{-1}$ ). In addition to these solid Earth signals the region is sensitive to local and remote atmospheric forcing (through wind and barometric pressure forcing) even on centennial time scales (Wakelin et al. 2003; Jevrejeva et al. 2005; Dangendorf et al. 2014a; Frederikse et al. 2016). The Baltic Sea is further strongly influenced by continental freshwater discharges controlling the haline properties in the ocean, but it is unclear by how far this decouples the local sea level from changes in the adjacent North Sea and North Atlantic Ocean (Jevrejeva et al. 2014).

Given the fact that the Northern European Shelf is one of the best-monitored oceanic regions in the world, many studies have analyzed the temporal and spatial structure of sea level changes along the coastline. Woodworth et al. (2009) report trends of spatially varying signs over the period 1901-2006 for the waters around the United Kingdom. These trends are qualitatively consistent with the crustal movement signatures inferred from geological information. After removing the crustal contribution from the observed tide gauge records, Woodworth et al. (2009) provide a geocentric MSLR estimate of $1.4 \pm 0.2 \mathrm{~mm} \mathrm{yr}^{-1}$ averaged for the entire United Kingdom. These analyses have been extended by Wahl et al. (2013) for the entire North Sea basin. The authors indicate an east-west gradient in MSLR with lower rates in the English Channel (1.2 \pm $0.1 \mathrm{~mm} \mathrm{yr}^{-1}$ ) and higher rates along the southeastern part of the German Wadden Sea $\left(1.6 \pm 0.1 \mathrm{~mm} \mathrm{yr}^{-1}\right)$. Dangendorf et al. (2014a) later attributed these regional differences mainly to changes in atmospheric forcing including an intensification of the predominantly occurring westerly winds leading to enhanced Ekman transport toward the southeastern coastlines. A similar spatial trend pattern is also visible at individual tide-gauge records in the Baltic Sea. While Ekman (1988) already noted a basin-scale increase in Baltic MSL of $1 \mathrm{~mm} \mathrm{yr}^{-1}$ from 1774 to 1984 , analyses of local twentieth-century trends inferred from individual tide gauge records point to lower geocentric MSLR rates (from $0.4 \pm 0.22 \mathrm{~mm} \mathrm{yr}^{-1}$ to $1.2 \pm 0.08 \mathrm{~mm} \mathrm{yr}^{-1}$ ) in the west (Barbosa 2008; Donner et al. 2012) and higher rates along eastern coastlines such as the Gulf of Riga (2.3-2.7 $\mathrm{mm} \mathrm{yr}^{-1}$; Suursaar and Sooäär 2007). Given the geographical proximity to the North
Sea, it seems natural that similar mechanisms are responsible for the observed MSLR patterns in both basins. Indeed, there are a number of studies pointing toward strong positive correlations between Baltic sea levels and the North Atlantic Oscillation (NAO), which is the leading mode of atmospheric circulation in the region (Andersson 2002; Jevrejeva et al. 2005; Zorita and Hünicke 2006; Barbosa 2008; Karabil et al. 2018). These positive correlations are spatially heterogeneous and characterized by a significant increase from west to east (Hünicke and Zorita 2008). In addition, the NAO has seen a slight increase over the second half of the twentieth century (Feser et al. 2015). This increase is consistent with positive long-term trends of average wind speeds in observations over central Scandinavia (Bierstedt et al. 2015) and an increase in the frequency of storms in reanalysis products over the southern North Sea and Baltic Sea between 1958 and 2001 (Weisse et al. 2005). The reported changes in large-scale atmospheric circulation (Lehmann et al. 2011) may therefore have affected Baltic Sea MSLR in two ways: first, increased westerly flow and decreasing pressure fields over the entire basin may have increased the total water mass transport from the North Sea into the Baltic, consequently leading to an increase in basinwide MSLR. Second, the same patterns are a likely explanation for the observed east-west gradient with generally higher trends along the eastern coastlines of the basin (through increased westerly flow). Both hypotheses are consistent with findings for the adjacent North Sea (Dangendorf et al. 2014a) but have not been thoroughly investigated for the Baltic Sea.

In addition to atmospheric forcing, a further potential mechanism explaining the east-west gradient of MSLR trends are changes in the thermohaline density structure of the Baltic Sea (please note that these are also affected by wind forcing). Meier and Kauker (2003) reported two pronounced mean salinity minima based on a $100-\mathrm{yr}$ hydrographical model reconstruction: one in the 1930s and another in the 1990s. However, they could not detect any long-term trend in the salinity fields over the last century. Lehmann et al. (2011) found a basinwide increase in sea surface temperature (SST) by $0.05 \mathrm{~K} \mathrm{yr}^{-1}$ for the last three decades, with highest values in the Gulf of Finland (Stramska and Białogrodzka 2015). Similarly, Belkin (2009) estimated that the warming rate during the last decades exceeded $0.1 \mathrm{~K} \mathrm{yr}^{-1}$ in the Baltic Sea, which is more than 7 times the global rate $\left(0.013 \mathrm{~K} \mathrm{yr}^{-1}\right)$. Therefore, redistribution of water masses due to changes in the baroclinic pressure gradient could also lead to a spatially nonuniform MSLR.

An important physical quantity in the Baltic Sea is the ice coverage. During winter, on average $50 \%\left(210000 \mathrm{~km}^{2}\right)$ of 

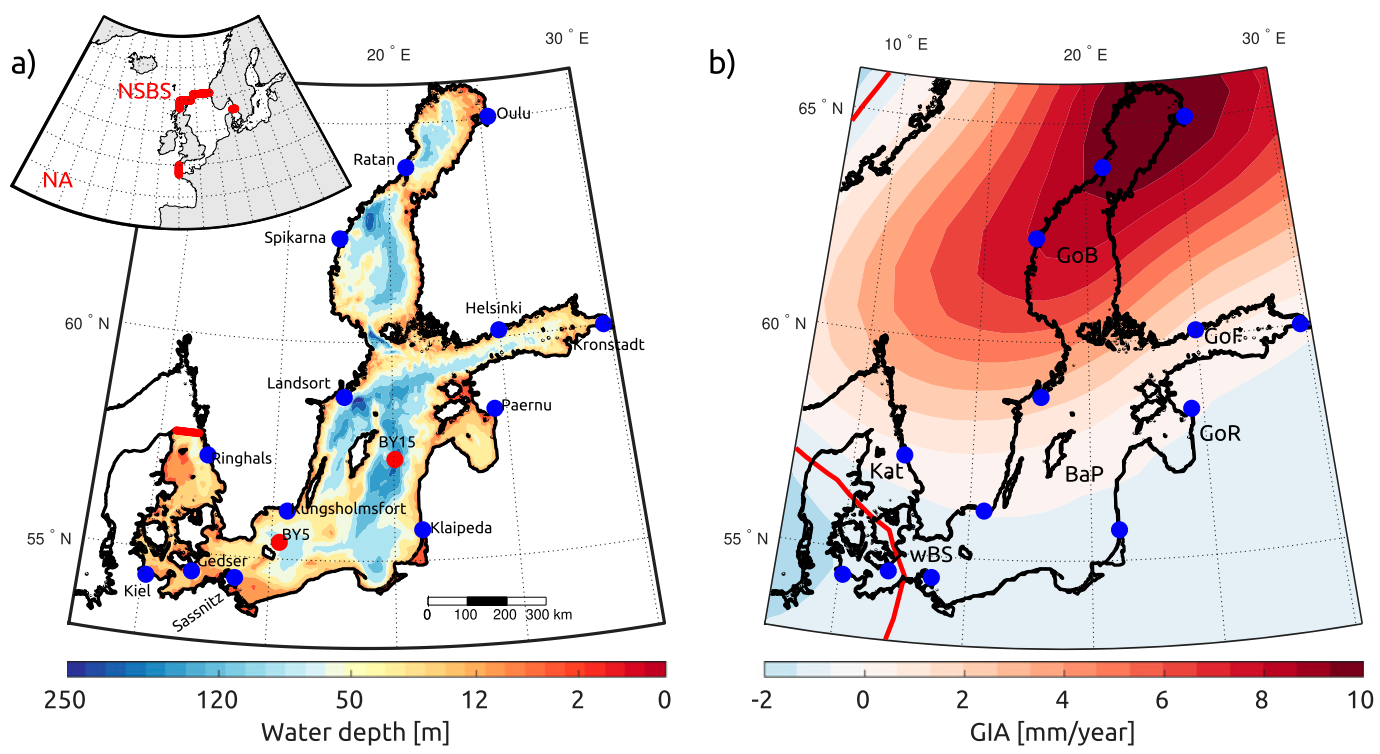

FIG. 1. (a) Model domain and bathymetry of the Baltic Sea. Blue dots indicate gauge stations and red dots salinity measurements. The abbreviations to mark specific regions are as follows: Kat, Kattegat; wBS, western Baltic Sea; BaP, Baltic proper; GoR, Gulf of Riga; GoF, Gulf of Finland; and GoB, Gulf of Bothnia. The inset shows the model domain of the NSBS model and the NA model. (b) GIA as estimated by Peltier (2004). The thick red line indicates zero land uplift.

the Baltic Sea is covered with ice (Omstedt et al. 2004). The general warming of the SST and the entire water column has caused a reduction of mean ice extent over the last 200 years by $416 \mathrm{~km}^{2} \mathrm{yr}^{-1}$ (Omstedt et al. 2004). Hünicke and Zorita (2016) already speculated that one effect of reduced ice cover in winter is a reduction of the missing values reported by the tide gauges affected by sea ice cover. However, this would only indirectly bias sea ice affected gauge stations. More directly, because of an increase in wind fetch, more water could potentially pile up at the coastline and therefore locally alter MSLR.

To summarize, although several studies have investigated sea level changes in the Baltic and proposed potential drivers of the observed changes, most studies have focused on individual tide-gauge records, certain coastline stretches, and/or only individual open ocean sites from satellite altimetry. Therefore, we still lack some insights into the spatial variation of sea level trends (Barbosa 2008; Hünicke and Zorita 2008; Donner et al. 2012). Moreover, little direct effort has been undertaken to separate and understand the individual processes contributing to the spatially heterogeneous sea level budget. To estimate the contributions of some potential drivers of the local MSLR, we designed a set of dedicated numerical experiments, covering the period 1950-2015. These experiments aim at disentangling the effects of changes in wind stress, air pressure, ice coverage, river discharge, and baroclinicity for the
Baltic Sea. Additionally, we try to estimate the contribution of the basinwide thermal expansion to the overall MSLR budget.

We organized the manuscript as follows: in section 2 we provide a description of the study region. In section 3, we present the data basis as well as the numerical ocean model setup and lay out the technique we used to estimate confidence levels for trend estimates. Additionally, we present the forcing and boundary conditions necessary to drive the ocean model for the period 1948-2015. Furthermore, to compute the uncertainty associated with the atmospheric forcing, we introduce a five-member atmospheric forcing ensemble to drive the ocean model for the period 1980-2005, which is common to all products. In section 4 we show some skill metrics used to assess the performance of the model in reproducing the state of the Baltic Sea. In section 5 we quantify the uncertainty caused by the choice of the atmospheric forcing. Section 6 is devoted to the presentation and discussion of trend estimates in MSL and the contributions of individual drivers. Moreover, we provide a basinwide budget of MSLR as well as some regional analysis. In the appendix we present further details of the atmospheric forcing ensemble.

\section{Study area}

The Baltic Sea is a semienclosed water body (see Fig. 1a), with a narrow connection to the North Sea (through the Danish Straits) and a double stratification 
characterized by a seasonal thermocline in summer and a strong permanent halocline. The halocline, at about 60-80-m depth, separates brackish surface water of about $7 \mathrm{psu}$ and deep water of about $12 \mathrm{psu}$. The interior of the Baltic Sea is dominated by boundary mixing due to the interaction of the halocline with the sloping bathymetry (Holtermann et al. 2014). The Baltic Sea shows a large spatial salinity gradient with surface salinities varying from 1-2 psu in the northern parts to 32 psu in the Kattegat. These large salinity variations are caused by the excess of river discharge, leading to a mean outflow through the Danish Straits (Reißmann et al. 2009). From 1902 to 1998, the average annual freshwater inflow to the Baltic amounts to $512 \mathrm{~km}^{3}$ with contributions from river runoff $\left(448 \mathrm{~km}^{3}\right)$ and net precipitation over the Baltic Sea $\left(64 \mathrm{~km}^{3}\right)$ (Meier and Kauker 2003). During the period 1950-2015, we estimated (based on our forcing discharge data) an increase in river runoff by $0.26 \pm 0.42 \mathrm{~km}^{3} \mathrm{yr}^{-1}$, caused by an increase in precipitation over northern Europe (van den Besselaar et al. 2012). The salinityinduced baroclinic pressure gradient is balanced by a barotropic gradient of $30 \mathrm{~cm}$ across the entire Baltic. The energy supply to the system originates from the wind and thermohaline processes at the surface (Reißmann et al. 2009). During winter, the northern and northeastern parts are covered with ice (Haapala et al. 2015), thus limiting the ocean-atmosphere exchange. Haapala et al. (2015) reported that the frequency and extent of sea ice cover is diminishing in this area due to rising temperatures. Similar findings are reported by Jevrejeva et al. (2004) or Omstedt et al. (2004). The latter estimated a reduction of mean ice extent of the last 200 years by $416 \mathrm{~km}^{2} \mathrm{yr}^{-1}$.

Tides, as a source of energy, are nearly absent and are effectively damped out by the Danish Straits. Additionally, land uplift movements due to GIA heavily influence the Baltic Sea (see Fig. 1b; also see Ekman 1996). GIA therefore leads to a relative sinking of the mean water level north of $59^{\circ} \mathrm{N}$.

\section{Methods}

\section{a. The ocean model}

To get a state estimate of the Baltic Sea for the period 1948-2015, we used a reduced version of the North Sea/Baltic Sea model from Gräwe et al. (2015) [see also Pätsch et al. (2017) and Placke et al. (2018)]. The model domain covers the Baltic Sea up to the zonal transect at the northern tip of Denmark (see Fig. 1a) and was resolved to approximately 1 nautical mile (nm; $1 \mathrm{~nm}=1.852 \mathrm{~km} ; \Delta \lambda=1 / 30^{\circ}, \Delta \phi=1 / 60^{\circ}$ ). The Baltic Sea model was the end member of a triple nesting hierarchy covering parts of the North Atlantic and the North Sea.

The hydrodynamic model core was the state-of-the-art coastal ocean model General Estuarine Transport Model (GETM; Klingbeil and Burchard 2013; Klingbeil et al. 2018). This study used 50 vertically terrain-following layers with adaptation toward stratification (Hofmeister et al. 2010) and a maximum surface layer thickness of $50 \mathrm{~cm}$. Lateral diffusion of momentum, salinity, and temperature was carried out along these model layers with a harmonic Smagorinsky diffusivity and a turbulent Prandtl number of 3. Vertical diffusivities were obtained from General Ocean Turbulence Model (GOTM; Umlauf and Burchard 2005), here based on a $k-\varepsilon$ model with the algebraic second-moment closure of Canuto et al. (2001). The second-order Superbee scheme with reduced numerical mixing (Klingbeil et al. 2014) was chosen for the advection of all prognostic quantities (including $k$ and $\varepsilon$ ). To account for ice coverage, for the present study GETM was extended by a thermodynamic ice model (fast growing ice) according to Winton (2000). A similar choice was made in the numerical experiments of Seifert et al. (2009) and Fennel et al. (2010). Although we have forcing data available for the period 1948-2015, we excluded the years 1948 and 1949 from the entire analysis due to spinup effects.

\section{b. Atmospheric forcing dataset}

A reference run covering the period 1948-2015 was forced by the atmospheric data from the CoastDat2 dataset of Geyer (2014). These originate from a regional reconstruction for the entire European continent with the atmospheric model COSMO-CLM (CCLM). The simulation was done for 1948-2015 with a horizontal grid size of $0.22^{\circ}(\approx 22 \mathrm{~km})$ in rotated coordinates. Reanalysis data of the global NCEP-NCAR dataset of Kalnay et al. (1996) were used as forcing and spectral nudging was applied (von Storch et al. 2000). To force the ocean model, we extracted from the CoastDat2 dataset hourly standard variables: $10-\mathrm{m}$ wind speed, $2-\mathrm{m}$ air temperature, 2-m specific humidity, total cloud cover, and precipitation.

\section{c. Open boundaries}

Six-hourly temperature and salinity profiles and 20-min surface elevations and depth averaged currents at the open boundary in the Kattegat were extracted from a model covering the North Sea and Baltic Sea with a spatial resolution of $2 \mathrm{~nm}$ [NSBS; see Fig. 1a, similar to Gräwe et al. (2015)]. This outer model was integrated for the period 1948-2015, driven by the CCLM atmospheric dataset (section 3b). The NSBS model was forced at its open boundaries in the English Channel 
and at the Northwestern Shelf with monthly mean profiles of temperature and salinity from the global data assimilating model GECCO2 (Köhl 2015). From the global model of Köhl (2015) we also extracted the large-scale baroclinically driven sea surface elevation to account for the changing pressure difference between the entrance of the English Channel and the Northern Shelf. To account for mean sea level rise, we adjusted the large-scale sea surface elevation fields by the linear trend obtained from the two boundary gauges at Brest and Lerwick. These observations were corrected for GIA (Peltier 2004). We additionally removed air pressure contributions from the gauge data at Brest and Lerwick to avoid double counting of air pressure trends. To provide additional high-frequency sea level forcing at the entrance of the English Channel and the Northern Shelf, the surge elevations along the open boundaries were extracted from a barotropic surge model of the North Atlantic (NA; see Fig. 1a; see also Gräwe et al. 2015) with a temporal resolution of $20 \mathrm{~min}$. Since the output of the surge model does not contain tidal information, the tidal elevations and depth-averaged tidal currents were predicted by the Oregon State University (OSU) tidal data inversion model (Egbert et al. 2010) and linearly added to the forcing obtained from the surge model.

\section{d. Riverine freshwater discharge}

To account for riverine freshwater fluxes, the daily discharges of 90 rivers were considered. The flow data were extracted from the Global Runoff Data Centre database. For the North Sea, daily observations for the main rivers (accounting for $80 \%$ of the North Sea wide discharge) were available. The remaining rivers were modeled with a climatologic annual cycle. For the Baltic Sea, only $60 \%$ could be covered with direct observations. For the remaining rivers, individual climatologic annual cycles were constructed. Afterward, the total annual discharge of all Baltic Sea rivers was computed and compared with the Baltic Marine Environment Protection Commission-Helsinki Commission (HELCOM) estimates (HELCOM 1986). Then, the climatologically rivers were rescaled such that the sum of observed discharge and scaled climatologically river discharge matched the HELCOM values.

\section{e. Separating individual MSLR drivers}

We conducted a series of model runs (see Table 4 below) to separate the potential drivers of MSLR, outlined in section 1. The reference run, $\operatorname{Exp}_{\text {ref, }}$ was a full baroclinic run, aiming at reproducing the hydrographical state and MSLR in the Baltic Sea within the period 1950-2015. In combination with a series of four additional barotropic runs with 25 vertical levels, we estimated the effect of the individual drivers by analyzing the differences in modeled MSLR. To provide consistent boundary data for the barotropic runs, we also had to rerun the outer NSBS model (always with CCLM atmospheric and GECCO2 boundary forcing) in a corresponding barotropic setting.

In the second run, $\operatorname{Exp}_{\mathrm{btr}}$, we switched off all baroclinic dynamics within the models (NSBS and Baltic Sea). To still account for the shielding effect of ice, we prescribed daily mean ice coverage, extracted from Exp pref $_{\text {. Taking }}$ the difference between $\operatorname{Exp}_{\text {ref }}$ and Exp $p_{b t r}$, we could separate the baroclinic contribution to MSLR $(\triangle B C L)$. In a third experiment, $\operatorname{Exp}_{\text {slp }}$, we kept the air pressure over NSBS and the Baltic Sea constant, with a uniform value of $101 \mathrm{hPa}$. This value represents the long-term spatial mean. Still, we applied daily mean ice coverage, extracted from $E x x p_{\text {ref- }}$ The difference between $E_{x p} p_{b t r}$ and $\operatorname{Exp}_{\text {slp }}$ thus indicates the direct contribution from air pressure $(\triangle \mathrm{SLP})$. To separate the direct effect of changes in river discharge, to MSLR ( $\triangle \mathrm{RIV}$ ) we conducted Exp $_{\text {riv. }}$ This experiment is similar to $\operatorname{Exp}_{\mathrm{btr}}$, except that we replaced the annually varying discharge by a fixed climatologically annual cycle. In the fifth experiment, Exp ice, we estimated the direct impact of changes in ice coverage, that is, the shielding effect of ice on MSLR $(\triangle \mathrm{ICE})$. For this, we replaced the prescribed daily ice fields from $\operatorname{Exp}_{\text {ref }}$, with a climatologically annual cycle.

Based on the contributions obtained directly from the performed sensitivity runs above, we calculated the impact of wind to MSLR ( $\triangle$ WIN) from

$$
\begin{aligned}
\operatorname{MSLR}\left(\operatorname{Exp}_{\text {ref }}\right)= & \Delta \mathrm{BCL}+\Delta \mathrm{SLP}+\Delta \mathrm{RIV}+\Delta \mathrm{ICE} \\
& +\Delta \mathrm{WIN}, \quad \text { and } \\
\Delta \mathrm{WIN}= & \operatorname{MSLR}\left(\operatorname{Exp}_{\text {ref }}\right)-(\Delta \mathrm{BCL}+\Delta \mathrm{SLP} \\
& +\Delta \mathrm{RIV}+\Delta \mathrm{ICE}) .
\end{aligned}
$$

The procedure was necessary since we cannot directly estimate the contribution due to wind by the difference between $\operatorname{Exp}_{\mathrm{btr}}$ and $\operatorname{Exp}_{\text {slp. }}$. The reason is the assimilation of the linear MSLR trends in the GECCO2 boundary conditions at the northwestern shelf edge. Thus, the direct difference would include contributions from changes in the North Sea.

Our assumption is that all effects add linearly to the overall MSLR. Since we only want to analyze the direct effects of the individual drivers, we assumed a linear superposition of the individual driver effects. Although higher-order or nonlinear effects exist, these are in principle contained in the estimated contribution by wind forcing. Moreover, we assumed that nonlinear effects are of secondary importance and that there are 
TABLE 1. Summary of tide gauge stations. VLM lists the average trends in sea level due to GIA and local vertical land movements from NKG2016LU (Vestøl et al. 2014) and estimated 95\% confidence intervals. The gauge data of Kronstadt were taken from Bogdanov et al. (2000). For the location of the stations see Fig. 1.

\begin{tabular}{|c|c|c|c|c|c|}
\hline Station & Observation period & Coverage & $\Delta t$ & VLM & Reference height system \\
\hline \multirow[t]{2}{*}{ Oulu } & 1950-2015 & $95 \%$ & Monthly & $-8.30 \pm 0.39 \mathrm{~mm} \mathrm{yr}^{-1}$ & N2000 \\
\hline & 1979-2015 & $99 \%$ & Hourly & & \\
\hline \multirow[t]{2}{*}{ Ratan } & 1950-2015 & $95 \%$ & Monthly & $-9.51 \pm 0.30 \mathrm{~mm} \mathrm{yr}^{-1}$ & RH2000 \\
\hline & 1978-2015 & $99 \%$ & Hourly & & \\
\hline \multirow[t]{2}{*}{ Spikarna } & 1968-2015 & $100 \%$ & Monthly & $-8.94 \pm 0.32 \mathrm{~mm} \mathrm{yr}^{-1}$ & RH2000 \\
\hline & 1978-2015 & $100 \%$ & Hourly & & \\
\hline \multirow[t]{2}{*}{ Helsinki } & $1950-2015$ & $100 \%$ & Monthly & $-3.69 \pm 0.42 \mathrm{~mm} \mathrm{yr}^{-1}$ & RH2000 \\
\hline & 1978-2015 & $100 \%$ & Hourly & & \\
\hline \multirow[t]{2}{*}{ Kronstadt } & 1950-93 & $100 \%$ & Monthly & $-1.41 \pm 0.22 \mathrm{~mm} \mathrm{yr}^{-1}$ & BS77 \\
\hline & 1978-2015 & $100 \%$ & Hourly & & \\
\hline \multirow[t]{2}{*}{ Landsort } & 1950-2006 & $100 \%$ & Monthly & $-4.58 \pm 0.38 \mathrm{~mm} \mathrm{yr}^{-1}$ & RH2000 \\
\hline & 1978-2015 & $100 \%$ & Hourly & & \\
\hline \multirow[t]{2}{*}{ Paernu } & 1950-2015 & $100 \%$ & Monthly & $-1.70 \pm 0.25 \mathrm{~mm} \mathrm{yr}^{-1}$ & BS77 \\
\hline & $2005-15$ & $100 \%$ & Hourly & & \\
\hline \multirow[t]{2}{*}{ Klaipeda } & 1950-2012 & $100 \%$ & Monthly & $-0.20 \pm 0.11 \mathrm{~mm} \mathrm{yr}^{-1}$ & PNP \\
\hline & $2008-15$ & $96 \%$ & Hourly & & \\
\hline \multirow[t]{2}{*}{ Sassnitz } & 1950-2015 & $100 \%$ & Monthly & $-0.09 \pm 0.06 \mathrm{~mm} \mathrm{yr}^{-1}$ & NHN \\
\hline & 1980-2015 & $96 \%$ & Hourly & & \\
\hline \multirow[t]{2}{*}{ Gedser } & 1950-2012 & $99 \%$ & Monthly & $-0.23 \pm 0.08 \mathrm{~mm} \mathrm{yr}^{-1}$ & NHN \\
\hline & 1950-2012 & $96 \%$ & Hourly & & \\
\hline \multirow[t]{2}{*}{ Kungsholmsfort } & 1950-2015 & $100 \%$ & Monthly & $-1.36 \pm 0.19 \mathrm{~mm} \mathrm{yr}^{-1}$ & RH2000 \\
\hline & 1978-2015 & $100 \%$ & Hourly & & \\
\hline \multirow[t]{2}{*}{ Kiel } & 1956-2015 & $100 \%$ & Monthly & $+0.04 \pm 0.14 \mathrm{~mm} \mathrm{yr}^{-1}$ & $\mathrm{NHN}$ \\
\hline & 1956-2015 & $96 \%$ & Hourly & & \\
\hline \multirow[t]{2}{*}{ Ringhals } & 1968-2015 & $95 \%$ & Monthly & $-2.50 \pm 0.28 \mathrm{~mm} \mathrm{yr}^{-1}$ & RH2000 \\
\hline & 1978-2015 & $96 \%$ & Hourly & & \\
\hline
\end{tabular}

no significant interactions between the individual drivers. Although wind can alter the baroclinic dynamics, the barotropic contributions dominates due to the shallowness of the Baltic Sea and the seasonal and regional limited stratification.

Since GETM is a volume conserving numerical model, the effect of thermal expansion is not included. Therefore, our reference run $\operatorname{Exp}_{\text {ref }}$ underestimates the total MSLR. Although the effect of thermal expansion is included in the boundary conditions for the outer NSBS model, local effects further add to this external signal. To estimate the contributions of local thermohaline expansion to the overall MSLR, we additionally computed the change in local sea level based on annual mean fields of temperature and salinity from the reference run.

\section{f. Gauge measurements}

For validation of the model estimates for MSLR, we extracted monthly MSL time series from 13 tide gauge stations around the Baltic coastline. These were collected from either the Permanent Service for Mean Sea Level (PSMSL; Holgate et al. 2013) or calculated from hourly tide gauge records provided by the corresponding national administrations (see Table 1). High-resolution tide gauge records were averaged to monthly values if at least $50 \%$ of data were available each month. If more than one data source was available, over different nonoverlapping periods, we merged the datasets to one long MSL record. Each tide gauge record has been corrected for the effects of vertical land movements due to land uplift and subsidence from GIA (Steffen et al. 2014) using the land uplift model from the Nordic Geodetic Commission (NKG2016LU; Vest $\varnothing 1$ et al. 2014). NKG2016LU is a semiempirical land movement model, developed by the Nordic-Baltic cooperation in the Nordic Geodetic Commission (NKG) Group of Geoid and Height Systems. To provide a measure of the uncertainty in the land uplift, we estimated the $95 \%$ confidence intervals (CIs) based on the estimates of Ekman (1996), Peltier (2004), Vestøl et al. (2014), and Peltier et al. (2015). The 95\% CIs are provided in Table 1. Furthermore, it is important to notice that a further uncertainty stems from crustal motion related to present-day mass changes (Riva et al. 2017), which is not considered here.

\section{g. Uncertainty of linear trend analysis}

Sea level time series have considerable intra-annual to multidecadal variability that is temporally correlated at different time scales (Beran 1992; Bos et al. 2014). These correlations indicate that each individual observation is 
TABLE 2. Summary of the atmospheric datasets. The analyzed reference and sensitivity runs for the period 1950-2015 (section 3e) are all based on CCLM forcing. The other forcing sets are used for the additional ensemble runs for the period 1980-2005 (section 3h).

\begin{tabular}{llccll}
\hline \hline \multicolumn{1}{c}{ Dataset } & \multicolumn{1}{c}{ Global forcing } & Coverage & $\Delta x$ & $\Delta t$ & \multicolumn{1}{c}{ Special comments } \\
\hline CCLM & NCEP-NCAR & $1948-2015$ & $19 \mathrm{~km}$ & Hourly & Spectral nudging (von Storch et al. 2000) \\
CCLM-ERAi & ERA-Interim & $1979-2016$ & $11 \mathrm{~km}$ & Hourly & Spectral nudging (von Storch et al. 2000) \\
CFSR & - & $1979-2015$ & $32 \mathrm{~km}$ & Hourly & Data assimilation (Saha et al. 2010) \\
BaltAn & ERA-40 & $1965-2005$ & $11 \mathrm{~km}$ & 6-hourly & Data assimilation (Gustafsson 2001) \\
RCAO & ERA-40 & $1961-2007$ & $44 \mathrm{~km}$ & 3-hourly & Free run \\
UERRA & ERA-40/ERA-Interim & $1961-2015$ & $11 \mathrm{~km}$ & Hourly & Data assimilation (Gustafsson 2001) \\
\hline
\end{tabular}

not independent of the previous one and effectively provides less information than an independent or noncorrelated observation. This behavior is often modeled as an autoregressive (AR) process estimating the significance of underlying long-term trends (Church and White 2011). The $\operatorname{AR}(p)$ model of order $p$ specifies that the variable depends linearly on its $p$ previous values. Independent of these short-term memory effect, there exist long-term correlations on multiannual and decadal time scales (Bos et al. 2014; Dangendorf et al. 2014b). Because of these temporal correlations, the standard errors of trend estimates increase significantly compared to traditional statistical tests, which assume no temporal correlations. Consequently, there is a high risk of falsely overestimating the significance of an observed trend when not accurately accounting for the presence of temporal correlations (Bos et al. 2014; Dangendorf et al. 2014b).

To avoid assumptions on the order of the AR process or other intrinsic temporal correlations, we followed the approach suggested by Franzke (2013), which relies on the surrogate data generating method proposed by Theiler et al. (1992) and Schreiber and Schmitz (1996), sometimes also called the "phase scrambling method." This method generates surrogate time series with the same autocorrelation function, identical power spectrum, and the same probability density function as the input time series. For each time series, we generated 1000 surrogate realizations to represent intrinsic climate fluctuations. For each realization we computed the linear trend to finally estimate the distribution of linear trends in the stationary surrogate data (Franzke 2012). Based on these empirical distributions we computed the $95 \%$ confidence intervals. An estimated trend is significantly different from zero if it exceeds these confidence intervals.

\section{h. Uncertainty due to atmospheric forcing}

Atmospheric/ocean reanalysis data show large spreads between different model products (Chepurin et al. 2014; Piecuch et al. 2016). Stryhal and Huth (2017) noted a variability in the representation of large-scale weather patterns in a set of reanalysis products, although these represent the same "state of the atmosphere." In a smaller and more regional study, Bierstedt et al. (2015) compared two datasets for the North Sea/Baltic Sea region. The authors detected notable differences in mean wind speed but also in the extremes. Thus, depending on the choice of forcing datasets different results can be expected. To cope with the variability and the arbitrary choice of CCLM as atmospheric forcing, we estimated the uncertainty in MSLR with an ensemble analysis. This ensemble covers the period 1980-2005 and consists of five additional state-of-the-art regional atmospheric datasets. This ensemble is built from four regional downscaling attempts: CCLM-ERAi (Geyer 2014), BaltAn (Luhamaa et al. 2011), UERRA (Ridal et al. 2017), and RCAO (Döscher et al. 2002). Additionally, we used data from the global model NCEP Climate Forecast System Reanalysis (CFSR; Saha et al. 2010). For a summary of the datasets see Table 2, and for short descriptions see the appendix.

Each model run was started from identical initial conditions, taken from the reference run covering 1950-2015 with the CCLM forcing (Geyer 2014). Except from the atmospheric forcing, all settings and parameters were identical. Please note that we took for all ensemble runs the boundary conditions created by the NSBS run with the CoastDat2 forcing dataset. This was necessary since not all atmospheric ensemble members cover the entire North Sea. Thus, these experiments do not include the uncertainties within the external contribution entering the Baltic Sea at the boundaries. Based on linear MSLR trends from each ensemble member we finally calculated the spread between individual products $(95 \% \mathrm{CIs})$, which adds to the statistical uncertainties described in section 3g. Please note, however, that this spread very likely overestimates the surface forcing uncertainty as it only covers the common period 1980-2015, that is, 50\% of the total investigation period (1950-2015). However, it can be regarded as an upper boundary.

\section{Validation of the reference run (1950-2015)}

\section{a. Sea level}

In Fig. 2 we provide a validation of the hourly (Fig. 2a) and monthly mean (Fig. 2b) sea surface height values 


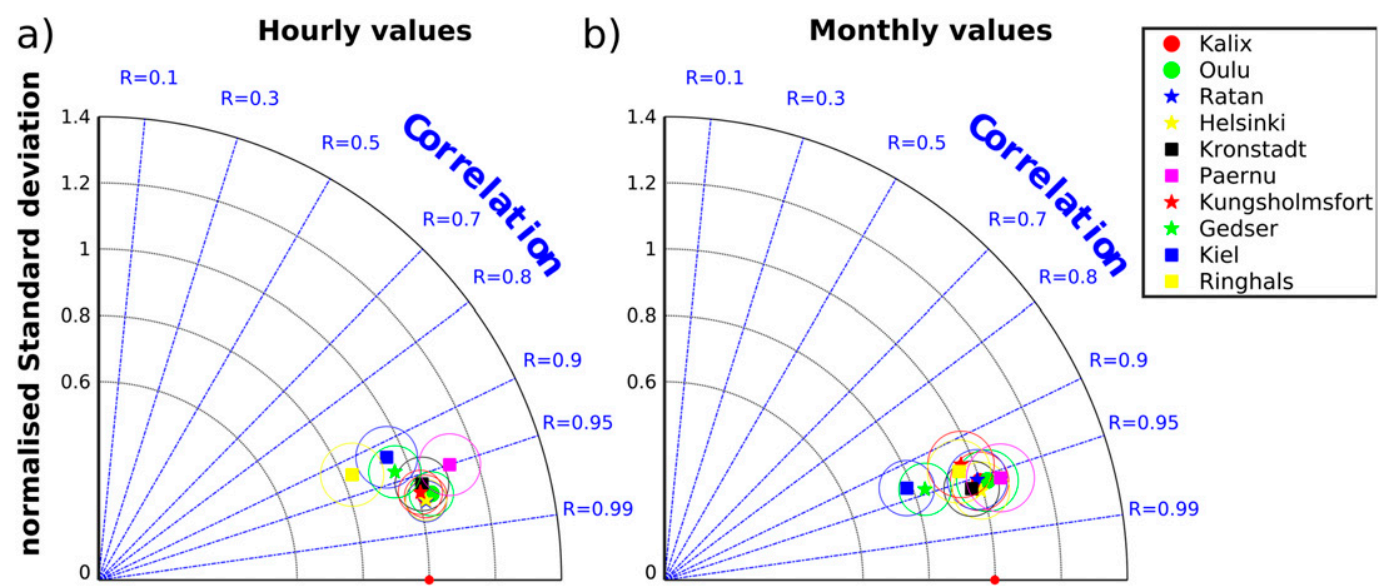

FIG. 2. Validation of sea surface elevation at selected stations: (a) instantaneous hourly values and (b) monthly mean values. For data coverage, please see Table 1 . The symbols mark the mean performance. The thin circles indicate the $95 \%$ confidence intervals.

using Taylor diagrams (Taylor 2001). For the hourly values (neither detided nor deseasonalized), correlations are generally higher than 0.9 . For stations in the Baltic Sea, the variability is overestimated by $10 \%$. Only in the most western part (Kiel) and the Kattegat the variability is underestimated. This can be partially explained by too low tidal amplitudes. The average root-mean-square error (RMSE) is below $8 \mathrm{~cm}$. The highest values are found for Ringhals with nearly $10 \mathrm{~cm}$, whereas the lowest RMSE was computed for Kungsholmsfort with $6 \mathrm{~cm}$. These RMSE values from our free model run are similar to the skill measure shown by the data assimilation runs of Fu et al. (2012) and Madsen et al. (2015).

For the monthly mean sea surface height we see a slightly lower performance. For most of the stations, the correlations are well above 0.95 . The stations in the western Baltic (Kiel, Gedser, and Kungsholmsfort) and Ringhals only show values well above 0.9 , which is probably due to the complex coastlines in this area. However, compared to the instantaneous hourly values, the variability is captured within $5 \%$ for nearly all stations. The only exceptions are Kiel and Gedser with an underestimation of $20 \%$. The average RMSE is close to $8 \mathrm{~cm}$ for all stations. Slightly elevated RMSEs are found in the Gulf of Bothnia with up to $9.5 \mathrm{~cm}$. A similar analysis with deseasonalized time series did not yield significantly different results.

As a further validation, in Table 3 we present the trend estimates of MSLR based on observations and model results. One can clearly see that for nearly all stations the model estimates agree well with the observed values. We found the highest observed values in Kronstadt with $2.72 \pm 2.08 \mathrm{~mm} \mathrm{yr}^{-1}$. Here the model estimates slightly lower values of $2.52 \pm 2.36 \mathrm{~mm} \mathrm{yr}^{-1}$.
Similarly, the observations and model agree in the western Baltic Sea, for instance at Gedser (observation $1.61 \pm 0.68 \mathrm{~mm} \mathrm{yr}^{-1}$, model $1.49 \pm 0.55 \mathrm{~mm} \mathrm{yr}^{-1}$ ). Moreover, the model can replicate the MSLR at Landsort (observation $2.08 \pm 1.06 \mathrm{~mm} \mathrm{yr}^{-1}$, model $\left.2.00 \pm 1.08 \mathrm{~mm} \mathrm{yr}^{-1}\right)$. Since the gauge at Landsort represents to a good approximation the average sea level of the Baltic Sea (Matthäus and Franck 1992), we can assume that the model captures the variations of the mean sea level in the Baltic Sea.

The only station where the model differs from the observed trend is Spikarna, at the western coast of the Gulf of Bothnia. Here, the model shows a trend of $1.86 \pm 1.39 \mathrm{~mm} \mathrm{yr}^{-1}$. This deviates by $1 \mathrm{~mm} \mathrm{yr}^{-1}$ from the observations of $2.84 \pm 1.13 \mathrm{~mm} \mathrm{yr}^{-1}$. At present, it is not clear what caused this large discrepancy. Since the model estimates at the two stations Landsort and Ratan (both located on the eastern coast of Sweden) agree well with the observations, we do not have a physical explanation as to why the observed MSLR in Spikarna should exceed the MSLR at Ratan by $0.8 \mathrm{~mm} \mathrm{yr}^{-1}$. Potential candidates to explain the deviations are an error in the GIA correction, other source of vertical land motion, or other problems with the vertical datum of the tide gauge.

\section{b. Baroclinic fields}

In Fig. 3 we present time series of temperature and salinity at the two stations BY5 and BY15 (see Fig. 1a for location in the western and central Baltic proper, respectively).

The surface salinity at station BY15 in the central Baltic proper shows the long-term variations as described by Meier and Kauker (2003). The model captures these variations with a bias of $-0.1 \pm 0.05 \mathrm{psu}$. The RMSE amounts to $0.21 \pm 0.04$ psu. If we compare the bottom 
TABLE 3. Comparison of trend estimates at selected stations for the period 1950-2015 and the model run. MSLR gives the trend estimate including the $95 \%$ confidence levels. "Fit CI" presents the estimates of the 95\% CI based on "phase scrambling" (see section 3g). The column "Ensemble CI" gives the $95 \%$ CI based on the ensemble runs (see Fig. 5b). The last column indicates the fitting period. Please note that the $95 \%$ CI for the model are a quadratic mean of Fit CI and Ensemble CI.

\begin{tabular}{|c|c|c|c|c|c|}
\hline \multirow[b]{3}{*}{ Station } & \multirow{3}{*}{$\frac{\frac{\text { Observation }}{\text { MSLR }}}{\left(\mathrm{mm} \mathrm{yr}^{-1}\right)}$} & \multicolumn{3}{|c|}{ GETM } & \multirow[b]{3}{*}{ Fit period } \\
\hline & & MSLR & Fit CI & Ensemble CI & \\
\hline & & $\left(\mathrm{mm} \mathrm{yr}^{-1}\right)$ & $\left(\mathrm{mm} \mathrm{yr}^{-1}\right)$ & $\left(\mathrm{mm} \mathrm{yr}^{-1}\right)$ & \\
\hline Oulu & $2.05 \pm 0.62$ & $1.95 \pm 0.74$ & \pm 0.65 & \pm 0.32 & 1950-2015 \\
\hline Ratan & $2.02 \pm 0.59$ & $1.86 \pm 0.72$ & \pm 0.68 & \pm 0.29 & 1950-2015 \\
\hline Spikarna & $2.84 \pm 1.13$ & $1.86 \pm 1.31$ & \pm 1.29 & \pm 0.23 & 1969-2015 \\
\hline Helsinki & $1.92 \pm 0.72$ & $1.87 \pm 0.93$ & \pm 0.89 & \pm 0.27 & $1950-2015$ \\
\hline Kronstadt & $2.72 \pm 2.08$ & $2.52 \pm 2.34$ & \pm 2.34 & \pm 0.18 & 1950-94 \\
\hline Paernu & $1.71 \pm 0.98$ & $1.72 \pm 1.05$ & \pm 1.00 & \pm 0.31 & 1952-2015 \\
\hline Landsort & $2.08 \pm 1.06$ & $2.00 \pm 0.98$ & \pm 0.95 & \pm 0.25 & 1950-2007 \\
\hline Klaipeda & $2.24 \pm 1.14$ & $2.37 \pm 0.97$ & \pm 0.90 & \pm 0.38 & 1950-2012 \\
\hline Sassnitz & $0.88 \pm 0.65$ & $1.19 \pm 0.61$ & \pm 0.55 & \pm 0.28 & 1955-2015 \\
\hline Gedser & $1.61 \pm 0.68$ & $1.49 \pm 0.55$ & \pm 0.46 & \pm 0.31 & 1950-2013 \\
\hline Kungsholmsfort & $1.62 \pm 0.43$ & $1.56 \pm 0.60$ & \pm 0.52 & \pm 0.31 & 1950-2015 \\
\hline Kiel & $1.34 \pm 0.41$ & $1.22 \pm 0.46$ & \pm 0.35 & \pm 0.31 & 1963-2015 \\
\hline Ringhals & $1.67 \pm 0.90$ & $1.66 \pm 0.89$ & \pm 0.86 & \pm 0.23 & 1968-2015 \\
\hline
\end{tabular}

values, a much higher variability is visible. At station BY5 in the Bornholm basin, we do clearly see signatures of the sporadic inflows from the North Sea (Franck et al. 1987; Schinke and Matthäus 1998). The model reproduces to a good degree the inflows, with a bias of $-0.17 \pm 0.20$ psu and a RMSE of $0.67 \pm 0.22$ psu. If we turn again to BY15, the bottom salinity as shown in Fig. 3c demonstrates that the inflows into the deeper basins are well matched. Moreover, the slow decrease in bottom salinity at BY15, during the stagnation periods 1998-2002 and 2007-10, indicates that internal mixing and thus the background diffusivity is properly reproduced by the model (Holtermann et al. 2014). The bias of $0.11 \pm 0.05$ psu and the RMSE of $0.23 \pm 0.04$ psu are similar to the data-assimilating reconstruction of Fu et al. (2012) with a RMSE of 0.27 psu and Liu et al. (2013), with a bias of -0.21 psu. We also see a similar performance for the bottom temperature at BY15 (Fig. 3d). The model captures the dynamics reasonably well with a warm bias of $0.28 \pm 0.08 \mathrm{~K}$ and a RMSE of $0.48 \pm 0.07 \mathrm{~K}$. However, please note that our simulation was a free run and thus fully conservative, which is not the case in the

a)

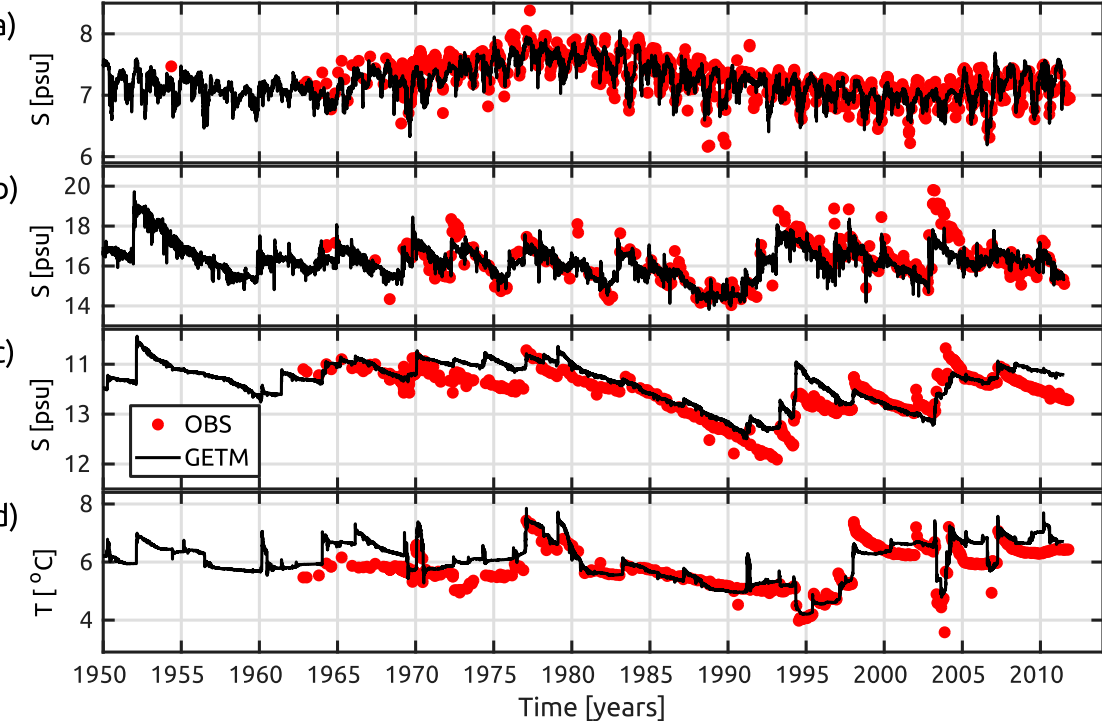

FIG. 3. Validation of salinity and temperature at selected stations: (a) surface salinity at BY15, (b) bottom salinity at BY5, (c) bottom salinity at BY15, and (d) bottom temperature at BY15. 

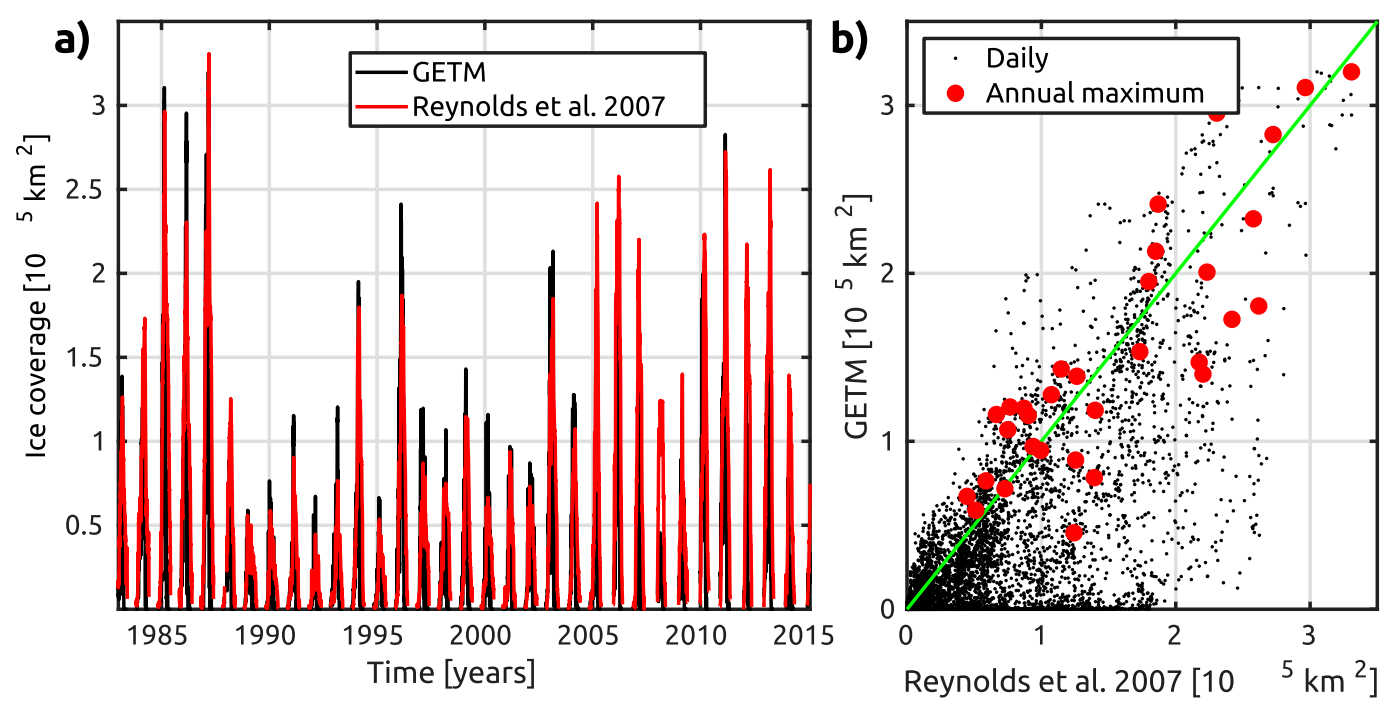

FIG. 4. Validation of ice coverage: (a) time series of daily ice coverage and (b) scatterplot of daily ice coverage and annual maximum. The green line indicates a perfect fit (slope of 1). The observations are taken from the dataset of Reynolds et al. (2007). The observational data cover the period 1983-2015.

data-assimilating runs of Fu et al. (2012) or Liu et al. (2013). For the shorter period 1970-99 the interested reader can find a more detailed validation of the baroclinic fields in Placke et al. (2018).

\section{c. Ice coverage}

In Fig. 4a, we show the daily mean ice coverage compared to the reconstruction of Reynolds et al. (2007). The model can reproduce the multiannual variations for the period 1983-2015. It captures the minimum values in the 1990s, but also the high values around 1985 and 2010-15. To have a better comparison, in Fig. $4 \mathrm{~b}$, we present the scatterplot of daily ice coverage (black dots) and annual maximum (red dots). For the maximum ice extent, no systematic error in the model performance is visible, only some scatter. However, for the daily values, an underestimation is present. Whereas the thermodynamic ice model (Winton 2000), captures the initial growth, it underestimates the total ice volume. Since the total ice mass is too low, the model predicts the first day of an ice-free Baltic on average 2-2.5 weeks too early. Anyhow, we believe that the performance of the thermodynamic ice model in GETM is sufficient to capture the shielding effect for the direct dynamical interaction between the atmosphere and the ocean.

\section{Uncertainty due to atmospheric forcing and ensemble variability (1980-2005)}

In Fig. 5a we present the GIA-corrected modeled MSLR for the period 1980-2005 as the ensemble mean of the six ocean simulations driven by the different atmospheric reanalysis products (Table 2). A southnorth gradient is visible. The highest values were found in the western Baltic Sea with $1.4 \mathrm{~mm} \mathrm{yr}^{-1}$, while the lowest values appeared in the Gulf of Bothnia and Gulf of Finland. However, the model ensemble also exhibits a significant spread between individual realizations. Figures $5 \mathrm{c}-\mathrm{h}$ show the anomalies in MSLR (after removing the ensemble mean) as response to the six different atmospheric forcing products. CCLM shows elevated values in the Gulf of Bothnia along the eastern Swedish coast. CCLM-ERAi causes a much stronger mean response with generally higher values. Only in the Baltic proper do we see values lower than the ensemble mean. In contrast, CFSR underestimates the MSLR along the coasts in the southern and central part. In the Gotland basin a positive anomaly is visible. BaltAn underestimates MSLR in most parts of the Baltic Sea, except in the Kattegat and the Baltic proper. RCAO leads to an underestimation in the Gulf of Bothnia and an overestimation in the southern and western Baltic. UERRA is close to the ensemble mean, with a slight negative anomaly in the central Baltic and slightly elevated values in the western Baltic.

Possible explanations for the large ensemble spread are differences in resolving the land-sea transition, a different representation of the wind curl over the central Baltic Sea, and a difference in the large-scale pressure gradient over the Baltic. However, the intention of the ensemble is not to validate and compare in detail each member and its deviation from the mean. Our assumption is that each member represents an equally likely realization of the "truth." The ensemble should only 

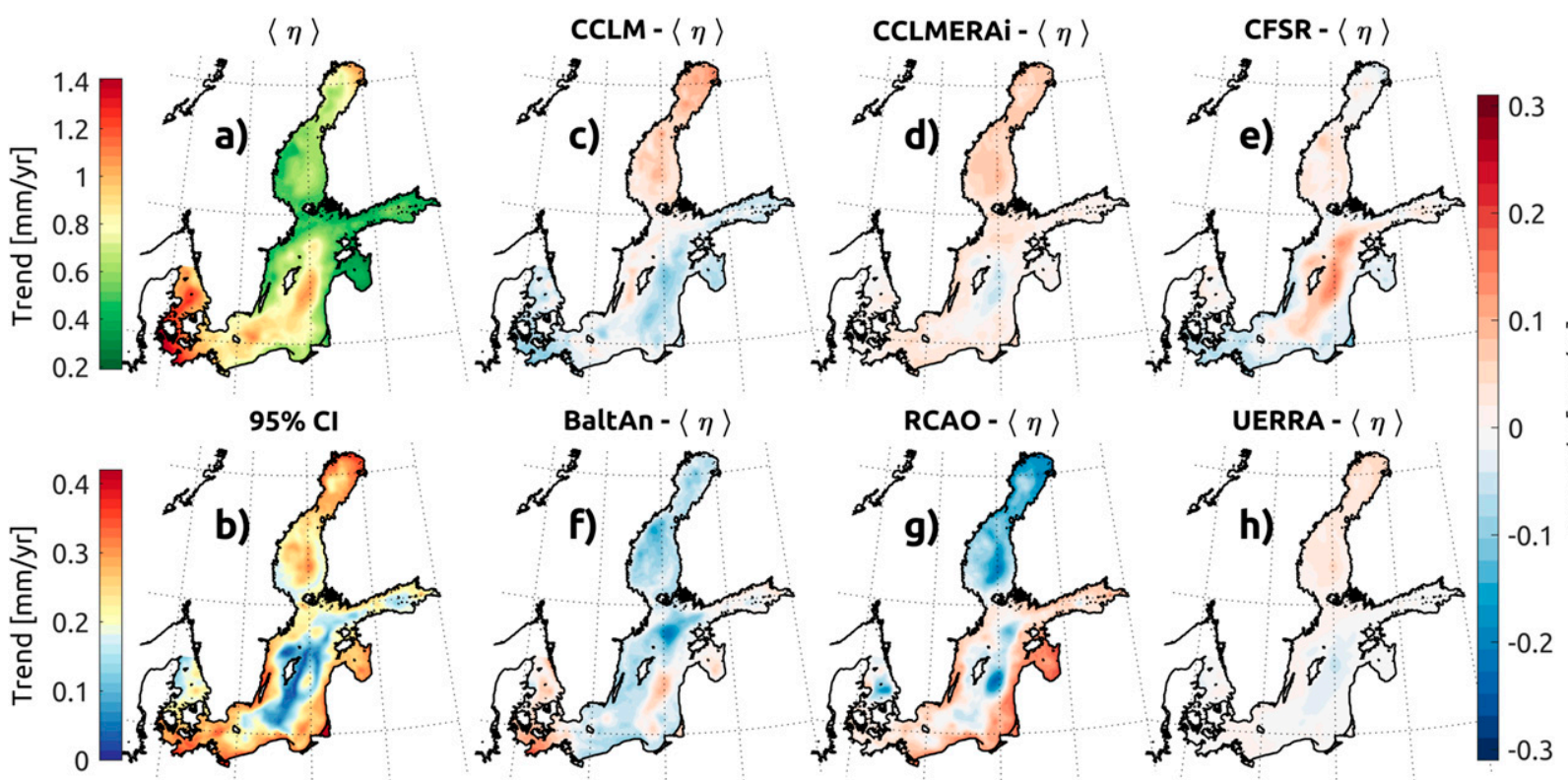

FIG. 5. (a) Ensemble mean of sea level rise for the period 1980-2005 and (b) 95\% CIs. Anomaly of sea level rise (by removal of the ensemble mean) for (c) CCLM, (d) CCLM-ERAi, (e) CFSR, (f) BaltAn, (g) RCAO, and (h) UERRA.

serve to estimate the uncertainty introduced by only picking one atmospheric forcing. Therefore, we present in Fig. 5b, based on the ensemble spread, the 95\% confidence intervals. The basin average of the $95 \%$ CI gives a value of $\pm 0.22 \mathrm{~mm} \mathrm{yr}^{-1}$. However, higher values can be found along the coastline, with $\pm 0.4 \mathrm{~mm} \mathrm{yr}^{-1}$. The lowest uncertainty is estimated for the Gotland basin with a $95 \%$ CI of $\pm 0.05 \mathrm{~mm} \mathrm{yr}^{-1}$. Table 3 summarizes the uncertainty due to the ensemble runs for selected stations. The highest variability can be found in the Gulf of Riga, the northern Gulf of Bothnia, the eastern coast of the Gotland basin, and the western Baltic Sea with a $95 \%$ CI larger than $0.3 \mathrm{~mm} \mathrm{yr}^{-1}$.

To estimate the $95 \%$ CI we had to rely on an ensemble of six members, covering only a period of 26 years. To test whether the $95 \%$ CI values converged to a stable value, we randomly subsampled the 26 years of data, starting from 10 years of data to 25 years. For these subsets of the original data, we estimated the $95 \%$ CI for each length of years. Thus, we could finally plot the convergence of the $95 \%$ CI for a certain length of data (not shown here). The analysis indicated that for fitting periods longer than 20 years, the $95 \%$ CI values converged to a stable value. Only for the eastern part of the Gulf of Finland, the 95\% CI still showed some variations. Thus, it is likely that we slightly overestimate the ensemble $95 \%$ CI in this region. Anyhow, for most parts of the Baltic Sea the $95 \%$ CI, as shown in Fig. 5b, gives a good estimation of the atmospheric uncertainty.

\section{Trends in mean sea level (1950-2015)}

In Fig. 6a we present the mean sea level rise estimated with linear trends over the period 1950-2015. We found lowest values in the western Baltic Sea with $1.2 \mathrm{~mm} \mathrm{yr}^{-1}$ and highest values at the eastern coast of the Gulf of Finland and in the Gulf of Riga, with $2.5 \mathrm{~mm} \mathrm{yr}^{-1}$. The external MSLR, as prescribed in the northern Kattegat, is $1.6 \mathrm{~mm} \mathrm{yr}^{-1}$. A thick blue line in Fig. 6a highlights this value. In the western Baltic Sea MSLR is lower than the external contribution. In the central and northern Baltic, the regional MSLR is clearly well above the values in the Kattegat. This indicates that the sea level in the Baltic Sea does not act like a bathtub uniformly filling up over the entire basin, driven by the MSLR in the North Sea and the adjacent North Atlantic. We give possible explanations for this in section 6a. In Fig. 6a we also marked the region (thick green line), where GIA and MSLR balance each other. This would manifest in a constant relative mean sea level (assuming persistent present day conditions). The regions northwest of Gotland and the entire Gulf of Bothnia have experienced a decreasing relative mean sea level.

In Fig. $6 \mathrm{~b}$ we present the $95 \%$ confidence intervals. These are a combination of the uncertainty due to temporal correlations (section $3 \mathrm{~g}$ ) and the atmospheric uncertainty due to the ensemble spread for the period 1980-2005 (Fig. 5b). Here we assumed that both confidence intervals represented independent Gaussian standard errors and that the ensemble spread 

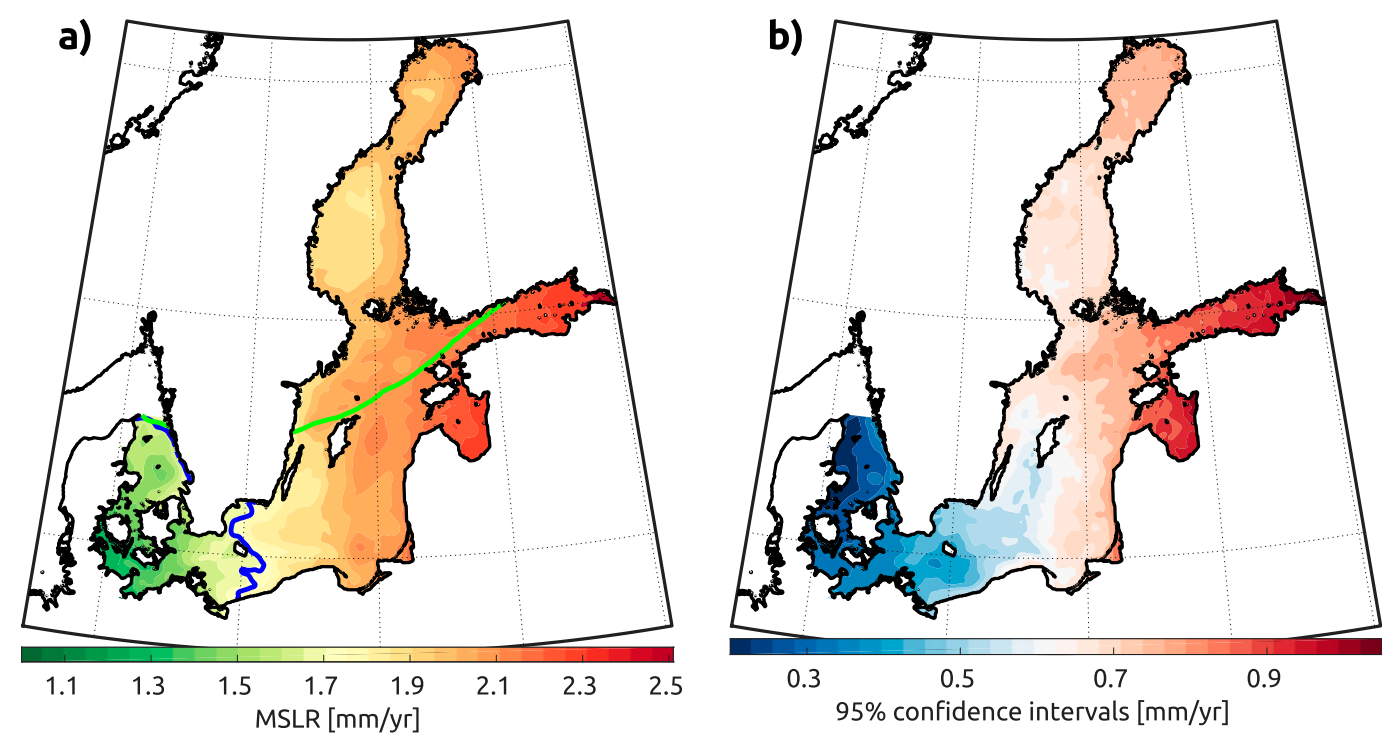

FIG. 6. (a) MSLR for the period 1950-2015. The thick blue line indicates the external MSLR of $1.6 \mathrm{~mm} \mathrm{yr}^{-1}$. The thick green line marks the balance between land uplift and MSLR. (b) Estimation of $95 \%$ confidence intervals as a quadratic mean of the uncertainty by temporal correlation and the atmospheric uncertainty due to the ensemble spread for the period 1980-2005.

for the period 1980-2005 is similar for the period 1950 2015 (i.e., a conservative estimate of the true uncertainty). The highest values are present in the Gulf of Finland $\left( \pm 1 \mathrm{~mm} \mathrm{yr}^{-1}\right)$ and the lowest $95 \%$ CI values are found in the western Baltic Sea $\left( \pm 0.3 \mathrm{~mm} \mathrm{yr}^{-1}\right)$. The pattern in $95 \%$ CI is well correlated with MSLR (Fig. 6a), which reflects the larger total sea level variability in the east (mainly due to wind forcing). Nonetheless, for the entire Baltic Sea MSLR is well above the $95 \%$ CI. Therefore, the analyzed MSLR in the Baltic Sea is statistically significantly different from zero.

\section{a. Decomposition of mean sea level rise}

In section 1 we introduced potential drivers influencing local MSLR in the Baltic Sea. By performing four additional sensitivity runs (Table 4) and simple subtraction, we could decompose the local MSLR into its individual drivers (i.e., the contributors to spatial variations in the Baltic Sea itself; Fig. 7). The largest contributions for spatially varying MSLR are coming from wind (Fig. 7a) and air pressure (Fig. 7b). Changes in the wind fields account for an additional $0.4 \mathrm{~mm} \mathrm{yr}^{-1}$ in the Gulf of Finland and Gulf of Riga, whereas we see a negative response in the western Baltic Sea with $-0.2 \mathrm{~mm} \mathrm{yr}^{-1}$. We will discuss the changes in the wind field as a driving mechanism in more detail in section $6 \mathrm{~b}$.

The response of the ocean to changes in air pressure exhibits a clear gradient through the basin (Fig. 7b), positive contributions of $0.3 \mathrm{~mm} \mathrm{yr}^{-1}$ appear in the northern part of the Baltic (Gulf of Bothnia) and negative contributions in the western Baltic Sea $\left(-0.2 \mathrm{~mm} \mathrm{yr}^{-1}\right)$. The pattern in the MSLR response looks similar to the second air pressure redundancy mode of Kauker and Meier (2003; see Fig. 3 therein). Moreover, it also mirrors the changes in the large-scale variations of the air pressure

TABLE 4. Summary of sensitivity runs (section 3e) to separate the individual contributions to MSLR.

\begin{tabular}{|c|c|c|c|c|c|}
\hline Run & Type & Air pressure & Rivers & Ice coverage & Analyzed contribution \\
\hline No. 1: Expref & Baroclinic & Hourly (CCLM) & Daily & Prognostic & Overall MSLR \\
\hline No. 2: $\operatorname{Exp}_{\mathrm{btr}}$ & Barotropic & Hourly (CCLM) & Daily & Daily $\left(\operatorname{Exp}_{\mathrm{ref}}\right)$ & $\begin{array}{c}\text { Baroclinicity }(\triangle B C L= \\
\left.\operatorname{Exp}_{\text {ref }}-\operatorname{Exp}_{b t r}\right)\end{array}$ \\
\hline No. 3: $\operatorname{Exp}_{\mathrm{slp}}$ & Barotropic & Constant $(101 \mathrm{hPa})$ & Daily & Daily $\left(\operatorname{Exp}_{\mathrm{ref}}\right)$ & $\begin{array}{l}\text { Air pressure }(\Delta \mathrm{SLP}= \\
\left.\operatorname{Exp}_{\mathrm{btr}}-\operatorname{Exp}_{\mathrm{slp}}\right)\end{array}$ \\
\hline No. 4: $\operatorname{Exp}_{\text {riv }}$ & Barotropic & Hourly (CCLM) & Climatology & Daily $\left(\operatorname{Exp}_{\mathrm{ref}}\right)$ & $\begin{array}{l}\text { River discharge }(\Delta \mathrm{RIV}= \\
\left.\text { Exp }_{\mathrm{btr}}-\text { Exp }_{\text {riv }}\right)\end{array}$ \\
\hline No. 5: $\operatorname{Exp}_{\text {ice }}$ & Barotropic & Hourly (CCLM) & Daily & Prescribed climatology & $\begin{array}{l}\text { Ice shielding }(\Delta \mathrm{ICE}= \\
\left.\operatorname{Exp}_{\mathrm{btr}}-\operatorname{Exp}_{\mathrm{ice}}\right)\end{array}$ \\
\hline
\end{tabular}




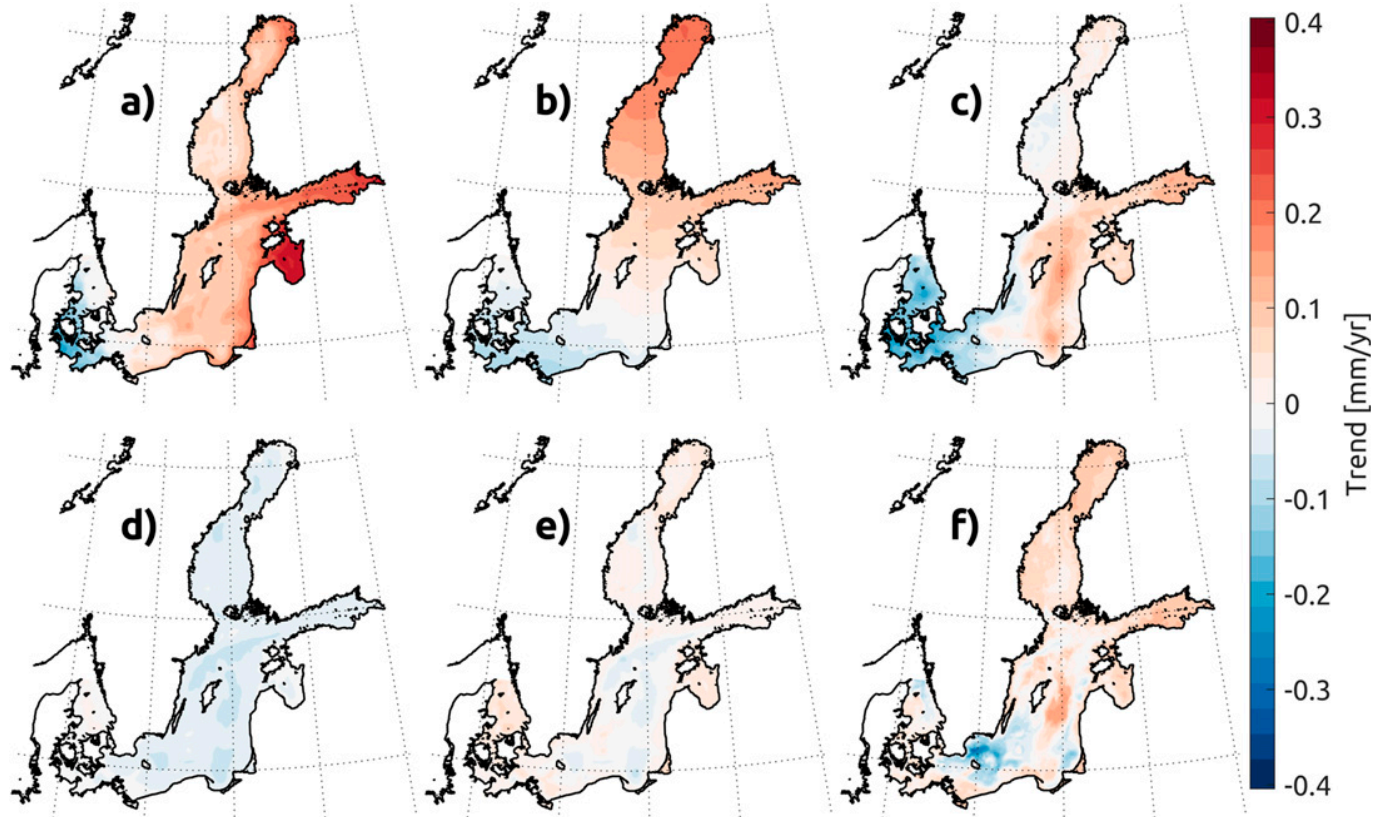

FIG. 7. Decomposition of mean sea level rise into (a) wind effects, (b) air pressure effects, (c) baroclinic response, (d) changes in ice coverage, (e) changes in river discharge, and (f) additional contribution due to thermal expansion. The analysis was done for the period 1950-2015. Please note that to recover the full picture of MSLR the spatially constant external MSLR of $1.6 \mathrm{~mm} \mathrm{yr}^{-1}$ has to be added.

fields, with a northward shift of the low pressure tracks (Omstedt et al. 2004; Lehmann et al. 2011). Due to the inverted barometer effect, the lowering of the air pressure over the northern Baltic leads to a rise in MSL. A regression analysis of the atmospheric air pressure fields indicate a total change of $2.5 \mathrm{~Pa} \mathrm{yr}^{-1}\left(-1.9 \mathrm{~Pa} \mathrm{yr}^{-1}\right.$ in the northern Baltic and $+0.6 \mathrm{~Pa} \mathrm{yr}^{-1}$ in the southwestern part). This would give a total change of $1.6 \mathrm{hPa}$ over the period 1950-2015 and thus a change of approximately $1.6 \mathrm{~cm}$ in MSL. Hence, the pattern seen in Fig. $7 \mathrm{~b}$ is simply a linear response to the inverse barometer effect.

The pattern in the baroclinic response (Fig. 7c) is correlated with the pattern of SST warming and increased runoff. The regions with the highest increase in baroclinic response agree with the spatial SST trend pattern estimated by Stramska and Białogrodzka (2015) showing largest warming trends in the Gulf of Finland and in the Baltic proper for the period 1982-2013. The negative trends in the western Baltic Sea can be related to the increase of freshwater runoff caused by higher precipitation (van den Besselaar et al. 2012). Increased freshwater in the Baltic Sea sets up a baroclinic pressure gradient driving saline inflows across the Danish Straits until a compensating opposite barotropic pressure gradient has adjusted. Since medium size inflows mainly affect the western Baltic Sea, the increased mean bottom salinity increases the density, thus lowering the sea level. A further driver of the baroclinic response are the changes in the wind fields (Table 5). Higher wind speeds or more wind days could potentially thicken the surface mixed layer and thus change the large-scale internal pressure gradient. Additionally, since GETM is volume conserving, a changing baroclinic pressure gradient can only redistribute volume. Therefore, the decrease in surface salinity and higher warming in the Gulf of Finland and the Baltic proper leads to a sea level rise in these regions. The other regions have to experience a drop in MSL until the barotropic and the baroclinic pressure gradient balance again.

The direct effects of changes in ice coverage (Fig. 7d) and river discharge (Fig. 7e) are only of minor importance. The reduction in ice coverage leads to a slowing of MSLR by $0.05-0.1 \mathrm{~mm} \mathrm{yr}^{-1}$. Since these changes are not significant, it is difficult to figure out the exact reasons. Our best guess is that due to the larger free surface area the effect of the wind stress is better distributed over a larger region. This gives on average a lower overall effect. The increase in MSLR by changes in direct river discharge are clearly attributed to the higher volume discharge into the Baltic (caused by higher precipitation rates over northern Europe; van den Besselaar et al. 2012). Therefore, the total contribution must be positive. Please note that this is only the direct contribution. The indirect effect, by changing the salinity and thus 
TABLE 5. Summary of the number of wind days per year and consecutive wind days per year, based on the CCLM dataset for the period 1950-2015. We only computed the mean values and the trends for the zonal component of the wind. Please note that the atmospheric statistic is only calculated over water.

\begin{tabular}{llcrrr}
\hline \hline & & $U_{10 \mathrm{~m}}<-10 \mathrm{~ms}^{-1}$ & $U_{10 \mathrm{~m}}<-5 \mathrm{~ms}^{-1}$ & $U_{10 \mathrm{~m}}<+5 \mathrm{~ms}^{-1}$ & $U_{10 \mathrm{~m}}<+10 \mathrm{~ms}^{-1}$ \\
\hline \multirow{2}{*}{ Wind days } & Mean (days) & $15.2 \pm 1.9$ & $83.0 \pm 4.1$ & $137.4 \pm 5.0$ & $32.7 \pm 3.9$ \\
& Trend (days decade & -1 \\
Duration & $-0.3 \pm 0.3$ & $-1.7 \pm 1.6$ & $2.9 \pm 1.8$ & $1.5 \pm 1.1$ \\
& Mean (days) & $2.8 \pm 0.3$ & $8.4 \pm 0.4$ & $14.6 \pm 0.6$ & $4.3 \pm 0.4$ \\
& Trend (days decade & -1 \\
& & $-0.1 \pm 0.1$ & $-0.1 \pm 0.2$ & $0.5 \pm 0.4$ & $0.2 \pm 0.1$ \\
\hline
\end{tabular}

altering the baroclinic pressure gradient, is already assessed in Fig. 7c.

Finally, we estimated the contributions due to thermal expansion as shown in Fig. 7f. Here we only account for the excess warming compared to the North Sea to avoid double counting. Rutgersson et al. (2015) discussed that the observed warming is usually highest in spring, and has been stronger in the northern regions. Similarly, Belkin (2009) reported that the Baltic Sea is the fastestwarming marginal sea on a global scale. The response of the Baltic Sea is that thermal expansion adds to the MSLR. We do see highest contributions in the Gotland basin, the Gulf of Bothnia, and the Gulf of Finland. However, we have to raise some caution here. We estimated the thermal expansion based on postprocessing of the temperature fields. Therefore, we cannot account for potential adjustments of the MSL due to the changed baroclinic/barotropic pressure gradient. Nonetheless, in section $6 \mathrm{c}$ we will discuss the Baltic Sea budget, which should be a reliable estimation of the basinwide effect.

\section{b. Wind-driven changes of MSLR}

In Fig. 7 we can identify two main drivers for changes in MSL: wind and air pressure. To uncover the impact of the wind field a more detailed analysis is needed.

At first, we computed changes in the mean wind speed. The average wind speed over water in the Baltic Sea region is $6.8 \mathrm{~m} \mathrm{~s}^{-1}$. A linear trend analysis revealed a positive trend of $0.016 \pm 0.023 \mathrm{~m} \mathrm{~s}^{-1}$ decade $^{-1}$. However, this trend is not significant. In a second step, we analyzed the mean wind speed for the winter months and the summer months separately. We see a decreasing trend during summer of $-0.010 \pm 0.024 \mathrm{~m} \mathrm{~s}^{-1}$ decade $^{-1}$, also not significant, whereas the mean winter winds increase. Here, the trend analysis yielded a positive trend of $0.089 \pm 0.066 \mathrm{~m} \mathrm{~s}^{-1} \mathrm{decade}^{-1}$. These findings are in agreement with Bierstedt et al. (2015).

Therefore, we conducted a more detailed analysis of the dominant zonal wind component to understand possible changes in the wind statistics. In Table 5 we summarize our findings for the changes in the zonal component of the wind for the period 1950-2015. Since the climate in northern Europe is influenced by westerlies, we do see more days with westerly $(137.4 \pm 5.0)$ rather than easterly $(83.0 \pm 4.1)$ winds. Please note that we counted here only the total number of days, independent of seasons and consecutive periods. In the analysis of trends, we detected a decrease in wind days experiencing easterlies $\left(-1\right.$ day decade $\left.^{-1}\right)$, whereas the number of days with westerly winds increases $\left(2\right.$ days decade $\left.{ }^{-1}\right)$. Over the entire period 1950-2015, this amounts to two weeks of more westerly winds. Due to more westerly winds, more water can pile up at eastern coasts and thus explain the faster MSLR in the Gulf of Finland and the Gulf of Riga (Fig. 6a). The increase in the number of days with westerly winds agrees with the findings of Lehmann et al. (2017). The authors detected an increase of cyclones north of $52^{\circ} \mathrm{N}$, which exposes the Baltic Sea to more westerly storms.

In addition, our analysis shows that the total duration of westerly wind periods increases on average by 0.5 days decade $^{-1}$ (Table 5), with an average value of 16 days $\mathrm{yr}^{-1}$ for wind speeds larger than $5 \mathrm{~m} \mathrm{~s}^{-1}$. For higher wind speeds $\left(>10 \mathrm{~m} \mathrm{~s}^{-1}\right)$, the increase is lower, but still rises with 0.2 days decade ${ }^{-1}$. This increase might also explain why the annual high water levels in the Gulf of Finland and Gulf of Riga rise faster than MSL (Barbosa 2008). Moreover, Lehmann et al. (2017) summarized that the number and percentage of deep cyclones increased over the period from 1948-2002. This could also explain the prolongation of westerly wind periods.

Feser et al. (2015) reviewed an increase in storminess from about the 1970s until the mid-1990s, and summarized that for the last 100 years large decadal variations exist. They could not detect a significant trend in changes in the mean wind speed. Since our analysis only covers the period 1950-2015, the results are clearly influenced by the increase in mean wind speed since the 1960s and 1970s, peaking in the mid-1990s (Weisse et al. 2005; Rutgersson et al. 2015). Nevertheless, for the last six decades, we detected an increase in the number of days with westerly components. Additionally, we also see a prolongation of westerly wind periods (Table 5). In combination, both factors can explain the increase in MSLR in the eastern part of the Baltic Sea and the lower than average MSLR in the western Baltic Sea. 


\section{c. Baltic Sea MSL budget}

Until now, we only discussed long-term trends. Therefore, in the following section, we will focus more on interannual to decadal variations of MSL in the Baltic. In Fig. 8 we show the contribution of the individual drivers, averaged over the entire Baltic Sea region, evolving over the entire simulation period. As expected, the MSL in the Baltic Sea is tightly linked to the mass entering the basin from the North Sea. However, from 1980 until 2000, the MSL in the Baltic was several $\mathrm{cm}$ higher than in the Kattegat. The reason was the elevated mean zonal wind speed during that period (Weisse et al. 2009; Feser et al. 2015). Moreover, during that period the MSL in the Baltic but also in the North Sea was well above the global average. During the last years, we see a plateau in Baltic MSL. This deviates from the significant acceleration observed in the global mean over the recent decades (Dangendorf et al. 2017). However, it can be expected that such deviations do not last longer than a few decades and that Baltic MSL will follow the global trends in the long term.

Figure 8 indicates that the external mass component from the North Sea is the largest contributor to the basinwide MSL. The time series of the Baltic Sea also shows the variation in the large-scale wind field, as discussed by Weisse et al. (2005). The wind contribution to the basin wide MSL correlates well with the increase in mean wind speed since the 1960s and 1970s, accompanied by a relative increase in the frequency of storms over the southern North Sea and Baltic Sea in the period 1960-2000. The effect of the peak in mean wind speed in the mid-1990s can also be seen in the study of Weisse and Weidemann (2017). The authors analyze the number of days per year where the gauge at Landsort exceeded the local long-term mean by at least $15 \mathrm{~cm}$ over at least 20 consecutive days. Weisse and Weidemann (2017) report that the number of these high-filling events increased from 30 days in the 1950s to $70-80$ days in the 1990 s. The envelope of the resulting time series matches well the shape of the time series of the wind contribution in Fig. 8. Changes in the air pressure provide a nearly constant offset to the MSL. Remarkably, the contribution due to thermal expansion shows an increasing tendency over the last decades. Here, the fastest warming in marginal seas, as reported by Belkin (2009), is the most likely explanation.

In the above discussion, we presented basinwide averages. As already shown in Fig. 6a, the Baltic Sea shows a pronounced east-west asymmetry in MSLR. Therefore, we present in Table 6 the regional averages of

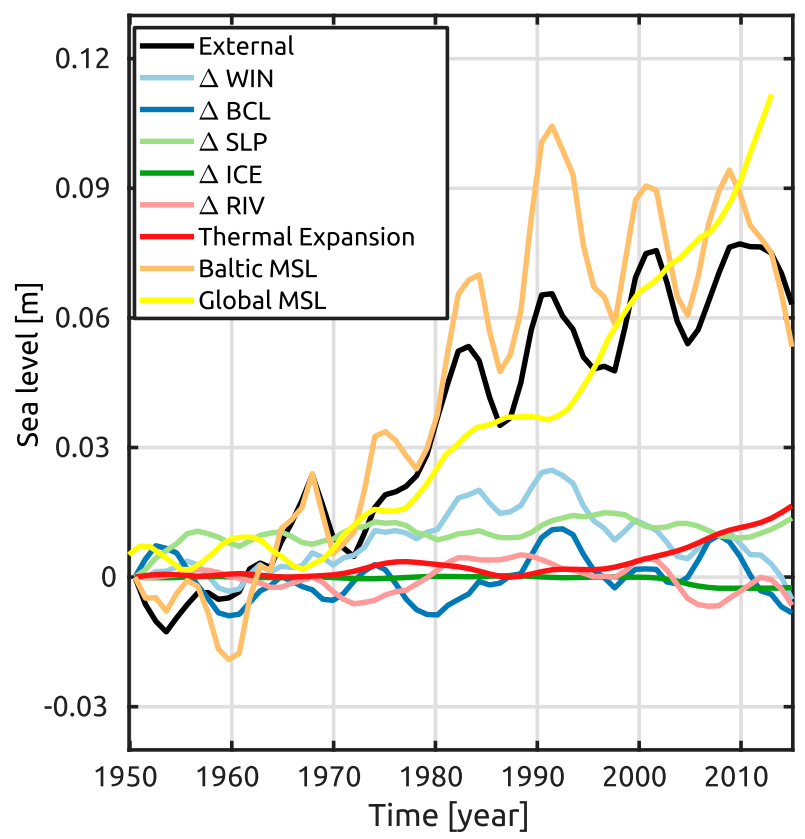

FIG. 8. Decomposition of the MSL rise in the Baltic Sea into its individual drivers. For comparison we also show an estimate of the global MSL (Dangendorf et al. 2017). The abbreviations in the legend are as follows: $\triangle \mathrm{BCL}$, baroclinic effects; $\triangle \mathrm{SLP}$, air pressure effects; $\triangle \mathrm{RIV}$, barotropic river contribution; $\triangle \mathrm{ICE}$, ice shielding; and $\Delta$ WIN, wind effects. For visualization purposes, we applied a 3 -yr low pass filter to smooth the time series.

MSLR in different subregions. The highest values can be found in the Gulf of Finland and the Gulf of Riga. In both regions, $30 \%$ of the total MSLR is explained by local effects. Nearly $0.3 \mathrm{~mm} \mathrm{yr}^{-1}$ MSLR is explained by changes in the wind field. Changes in the air pressure are also important. Of similar magnitude are contributions from changes in the baroclinic fields. Especially for the northern and northeastern part of the Baltic Sea, we see nonnegligible thermal expansion effects. In contrast, the western Baltic Sea follows closely the external forcing, and only $5 \%$ of MSLR is attributed to local dynamics. In the western Baltic the effect of a changed air pressure field vanishes.

\section{Summary}

We analyzed the output of an ocean model covering the entire Baltic Sea with a resolution of $1 \mathrm{~nm}$, the end member of a triple nesting hierarchy starting at the North Atlantic. The analyzed model run covered the period 1950-2015. A regression analysis of the monthly sea levels indicated a spatially nonuniform MSLR, with higher values in the eastern and northwestern part of the Baltic Sea and lower than average values in the western Baltic Sea. Based on dedicated control 
TABLE 6. Decomposition of MSLR into the individual drivers and for different regions of the Baltic Sea (see Fig. 1). The individual contributions are as follows: $\triangle \mathrm{BCL}$, baroclinic effects; $\triangle \mathrm{SLP}$, air pressure effects; $\triangle \mathrm{RIV}$, barotropic river contribution; $\Delta \mathrm{ICE}$, ice shielding; and $\Delta$ WIN, wind effects. Please note that the $95 \%$ CIs are only given as Fit CI (section $3 \mathrm{~g}$ ).

\begin{tabular}{|c|c|c|c|c|c|c|}
\hline Region & Baltic Sea & wBS & $\mathrm{BaP}$ & GoR & GoF & GoB \\
\hline External & \multicolumn{6}{|c|}{$1.60 \pm 0.45$} \\
\hline Regional & $0.48 \pm 0.13$ & $0.11 \pm 0.11$ & $0.48 \pm 0.16$ & $0.67 \pm 0.18$ & $0.74 \pm 0.17$ & $0.61 \pm 0.14$ \\
\hline$\Delta \mathrm{WIN}$ & $0.22 \pm 0.24$ & $0.10 \pm 0.19$ & $0.24 \pm 0.32$ & $0.30 \pm 0.45$ & $0.28 \pm 0.36$ & $0.21 \pm 0.24$ \\
\hline$\Delta \mathrm{SLP}$ & $0.11 \pm 0.09$ & $0.00 \pm 0.07$ & $0.09 \pm 0.08$ & $0.11 \pm 0.12$ & $0.16 \pm 0.15$ & $0.18 \pm 0.17$ \\
\hline$\triangle \mathrm{BCL}$ & $0.05 \pm 0.16$ & $-0.06 \pm 0.13$ & $0.07 \pm 0.21$ & $0.10 \pm 0.18$ & $0.11 \pm 0.19$ & $0.04 \pm 0.14$ \\
\hline$\Delta \mathrm{ICE}$ & $-0.01 \pm 0.03$ & $-0.02 \pm 0.03$ & $-0.01 \pm 0.04$ & $-0.03 \pm 0.02$ & $-0.02 \pm 0.02$ & $-0.02 \pm 0.03$ \\
\hline$\Delta \mathrm{RIV}$ & $0.06 \pm 0.10$ & $0.07 \pm 0.08$ & $0.05 \pm 0.11$ & $0.07 \pm 0.10$ & $0.07 \pm 0.09$ & $0.07 \pm 0.11$ \\
\hline Thermal expansion & $0.06 \pm 0.17$ & $0.02 \pm 0.16$ & $0.04 \pm 0.20$ & $0.11 \pm 0.22$ & $0.14 \pm 0.20$ & $0.13 \pm 0.17$ \\
\hline$\Sigma$ & $2.08 \pm 0.17$ & $1.71 \pm 0.16$ & $2.08 \pm 0.20$ & $2.27 \pm 0.22$ & $2.34 \pm 0.20$ & $2.21 \pm 0.17$ \\
\hline
\end{tabular}

experiments, we could separate the MSLR into different contributions.

Below, we summarize our main findings:

1) MSLR (corrected for the relative sea level contribution from GIA) in the Baltic Sea has been estimated by $2.08 \pm 0.49 \mathrm{~mm} \mathrm{yr}^{-1}$ over the period 1950-2015. This value is slightly larger than the simultaneous global mean of $1.63 \pm 0.32 \mathrm{~mm} \mathrm{yr}^{-1}$ (Dangendorf et al. 2017), as well as the adjacent southeastern North Sea $\left(1.94 \pm 0.36 \mathrm{~mm} \mathrm{yr}^{-1}\right.$ over 1940-2008; Albrecht et al. 2011). The elevated MSLR can be explained by intensified westerly winds pushing more water mass into the basin as well as a poleward shift of low pressure systems increasing the local sea level via the inverted barometer effect.

2) The MSLR within the Baltic Sea is not uniform, but rather shows a pronounced east-west asymmetry with values ranging from $1.71 \pm 0.34 \mathrm{~mm} \mathrm{yr}^{-1}$ in the western part to $2.34 \pm 0.91 \mathrm{~mm} \mathrm{yr}^{-1}$ in the northeastern Gulf of Finland. This asymmetry can mainly be attributed to wind and pressure effects acting differently on the oppositional directed coastlines in the east and west. For example, while $65 \%$ of the high MSLR rates in the Gulf of Finland are induced by an externally forced and uniform mass signal entering the Baltic from the North Sea, $25 \%$ of the elevated rates are the result of local wind and pressure effects.

3) We do see effects of a changed internal pressure gradient (baroclinic response). The baroclinic response is likely caused by a combination of warming and increased runoff. We found maximum positive contributions of $0.3 \mathrm{~mm} \mathrm{yr}^{-1}$ in the northern part of the Baltic (Gulf of Bothnia). These changes amount to roughly $10 \%$ of the total change.

4) Other effects, such as ice coverage and river discharge, are able to alter regional hydrodynamics but have little impact of the total MSLR.
5) Although the trend estimates based on an ensemble of different atmospheric forcing products show a considerable spread, the impact on the basinwide trend of $2.08 \pm 0.49 \mathrm{~mm} \mathrm{yr}^{-1}$ over the period $1950-2015$ is about $\pm 0.22 \mathrm{~mm} \mathrm{yr}^{-1}$ and of minor importance.

6) In the Gulf of Bothnia the high land uplift (GIA) by far exceeds the local MSLR.

Acknowledgments. Observational data were kindly provided by the Federal Maritime and Hydrographic Agency of Germany (BSH), the Defense Centre for Operational Oceanography (DCOO) Denmark, the Swedish Meteorological and Hydrological Institute (SMHI), the Danish Meteorological Institute (DMI), the Estonian Environment Agency (EEA), the Environmental Protection Agency Lithuania (EPA), the Permanent Service for Mean Sea level (PSMSL), the Federal Waterways and Shipping Administration Germany (WSV), the Centre for Environmental Predictions (CEFAS), and the Baltic Marine Environment Protection Commission-Helsinki Commission (HELCOM). The North-German Supercomputing Alliance (HLRN) provided supercomputing power. Ulf Gräwe was supported by grants (FKZ: 03F0747C) from the Ministry for Education, Science, Research and Technology (BMBF), Germany. The data analysis and storage was supported by BMBF project PROSO (FKZ: 03F0779A). Knut Klingbeil was financed by the Collaborative Research Centre TRR 181 on Energy Transfer in Atmosphere and Ocean funded by the German Research Foundation (project number 274762653). Jessica Kelln and Sönke Dangendorf acknowledge the KFKI for the funding of the AMSel-Ostsee and MSL Absolut project. All authors acknowledge the help of Bronwyn Cahill, for giving the paper the final touch. Finally, Ulf Gräwe thanks the German Railway for providing a comfortable environment on the trains where most of the typesetting of this paper was done. 


\section{APPENDIX}

\section{Atmospheric Forcing Datasets}

\section{a. CCLM-ERAi}

We used a second dataset, based on COSMO-CLM, covering the period 1979-2015. Whereas for CCLM the driving global model was NCEP-NCAR, here ERAInterim was used (Dee et al. 2011). The model region is similar to CCLM. In comparison to CCLM, the horizontal grid has now a resolution of $0.11^{\circ}(\approx 11 \mathrm{~km})$ in rotated coordinates. Again, spectral nudging was applied (von Storch et al. 2000). The atmospheric data are provided with a temporal resolution of $1 \mathrm{~h}$.

\section{b. CFSR}

The NCEP Climate Forecast System Reanalysis (CFSR; Saha et al. 2010) covers the period from 1979 to 2010. From 2011 onward, the CFSR runs with an increased resolution of the atmospheric model. The CFSR is executed as a global, high-resolution coupled atmosphere-ocean-land surface-sea ice system. The atmosphere resolution is $\approx 38 \mathrm{~km}$ (from 2011 onward $\approx 25 \mathrm{~km}$ ). Most available in situ and satellite observations were included in the CFSR. The atmospheric fields are provided at an hourly time resolution and are distributed by the $\mathrm{Na}$ tional Climatic Data Center (NCDC; now known as NCEI) and NCAR.

\section{c. BaltAn}

The BaltAn reanalysis comprises meteorological data for the Baltic Sea region for the time period 1965-2005 (Luhamaa et al. 2011). For data assimilation and hindcast, the numerical weather prediction model High Resolution Limited Area Model (HIRLAM) is applied, with 11-km horizontal and 60-layer vertical resolution. Reanalysis includes three-dimensional weather analysis data. Standard surface observations and meteorological soundings together with ship and buoy measurements from the WMO observational network are used in the analysis (Gustafsson 2001). Boundary conditions are obtained from the ECMWF ERA-40 global reanalysis (Uppala et al. 2005). The model output is provided with a time resolution of $6 \mathrm{~h}$.

\section{d. $R C A O$}

The downscaling simulations of the Rossby Centre Atmosphere Ocean model (RCAO; Döscher et al. 2002) covers the European continent, parts of the North Atlantic, the Nordic Seas, and the Arctic. The model was run for the period 1961-2007. The atmospheric model has a resolution of $44 \mathrm{~km}$ and 24 vertical hybrid levels.
Boundary conditions are also obtained from the ERA40 global reanalysis (Uppala et al. 2005). Data are provided with a time step of $3 \mathrm{~h}$. Please note that the RCAO simulation is a free run, only driven by the ERA-40 boundary conditions.

\section{e. UERRA}

Within the EU project "Uncertainties in Ensembles of Regional Re-Analyses" (UERRA) a regional hindcast covering Europe was performed (Ridal et al. 2017). The dataset is based on ARPEGE/Aladin (Bubnová et al. 1995), covering the period 1961-2015. ERA-40 and ERA-Interim (Dee et al. 2011) were used as driving global models. The dataset grid has a resolution of $0.11^{\circ}$ $(\approx 11 \mathrm{~km})$ in rotated coordinates. The model output is provided with a time resolution of $1 \mathrm{~h}$.

\section{REFERENCES}

Albrecht, F., T. Wahl, J. Jensen, and R. Weisse, 2011: Determining sea level change in the German Bight. Ocean Dyn., 61, 20372050, https://doi.org/10.1007/s10236-011-0462-z.

Andersson, H. C., 2002: Influence of long-term regional and largescale atmospheric circulation on the Baltic Sea level. Tellus, 54A, 76-88, https://doi.org/10.1034/j.1600-0870.2002.00288.x.

Barbosa, S. M., 2008: Quantile trends in Baltic Sea level. Geophys. Res. Lett., 35, L22704, https://doi.org/10.1029/2008GL035182.

Belkin, I. M., 2009: Rapid warming of large marine ecosystems. Prog. Oceanogr., 81, 207-213, https://doi.org/10.1016/ j.pocean.2009.04.011.

Beran, J., 1992: Statistical methods for data with long-range dependence. Stat. Sci., 7, 404-416, https://doi.org/10.1214/ ss/1177011122.

Bierstedt, S. E., B. Hünicke, and E. Zorita, 2015: Variability of wind direction statistics of mean and extreme wind events over the Baltic Sea region. Tellus, 67A, 29073, https://doi.org/ 10.3402/tellusa.v67.29073.

Bogdanov, V. I., M. Y. Medvedev, V. A. Solodov, Y. A. Trapeznikov, G. A. Troshkov, and A. Trubitsina, 2000: Mean monthly series of sea level observations (1777-1993) at the Kronstadt gauge. Finnish Geodetic Institute, 34 pp., https:/www.psmsl.org/data/ longrecords/ReportsFGI_2000_1.pdf.

Bos, M. S., S. D. P. Williams, I. B. Araujo, and L. Bastos, 2014: The effect of temporal correlated noise on the sea level rate and acceleration uncertainty. Geophys. J. Int., 196, 1423-1430, https://doi.org/10.1093/gji/ggt481.

Bubnová, R., G. Hello, P. Bénard, and J.-F. Geleyn, 1995: Integration of the fully elastic equations cast in the hydrostatic pressure terrain-following coordinate in the framework of the ARPEGE/Aladin NWP System. Mon. Wea. Rev., 123, 515-535, https://doi.org/10.1175/1520-0493(1995)123<0515: IOTFEE $>2.0 . \mathrm{CO} ; 2$.

Canuto, V. M., A. Howard, Y. Cheng, and M. S. Dubovikov, 2001: Ocean turbulence. Part I: One-point closure model-momentum and heat vertical diffusivities. J. Phys. Oceanogr., 31, 14131426, https://doi.org/10.1175/1520-0485(2001)031<1413: OTPIOP $>2.0 . \mathrm{CO} ; 2$.

Cazenave, A., and W. Llovel, 2010: Contemporary sea level rise. Annu. Rev. Mar. Sci., 2, 145-173, https://doi.org/10.1146/annurevmarine-120308-081105. 
_ - and Coauthors, 2018: Global sea-level budget 1993-present. Earth Syst. Sci. Data, 10, 1551-1590, https://doi.org/10.5194/ essd-10-1551-2018.

Chepurin, G. A., J. A. Carton, and E. Leuliette, 2014: Sea level in ocean reanalyses and tide gauges. J. Geophys. Res. Oceans, 119, 147-155, https://doi.org/10.1002/2013JC009365.

Church, J. A., and N. J. White, 2011: Sea-level rise from the late 19th to the early 21 st century. Surv. Geophys., 32, 585-602, https://doi.org/10.1007/s10712-011-9119-1.

,,-- R. Coleman, K. Lambeck, and J. X. Mitrovica, 2004: Estimates of the regional distribution of sea level rise over the 1950-2000 period. J. Climate, 17, 2609-2625, https://doi.org/ 10.1175/1520-0442(2004)017<2609:EOTRDO>2.0.CO;2.

— — - T. Aarup, W. S. Wilson, P. L. Woodworth, C. M. Domingues, J. R. Hunter, and K. Lambeck, 2008: Understanding global sea levels: Past, present and future. Sustain. Sci., 3, 9-22, https://doi.org/10.1007/s11625-008-0042-4.

Dangendorf, S., F. M. Calafat, A. Arns, T. Wahl, I. D. Haigh, and J. Jensen, 2014a: Mean sea level variability in the North Sea: Processes and implications. J. Geophys. Res. Oceans, 119, 6820-6841, https://doi.org/10.1002/2014JC009901.

—, D. Rybski, C. Mudersbach, A. Müller, E. Kaufmann, E. Zorita, and J. Jensen, 2014b: Evidence for long-term memory in sea level. Geophys. Res. Lett., 41, 5530-5537, https://doi.org/10.1002/2014GL060538.

— , M. Marcos, G. Wöppelmann, C. P. Conrad, T. Frederikse, and R. Riva, 2017: Reassessment of 20th century global mean sea level rise. Proc. Natl. Acad. Sci. USA, 114, 5946-5951, https://doi.org/10.1073/pnas.1616007114.

Dee, D. P., and Coauthors, 2011: The ERA-Interim reanalysis: Configuration and performance of the data assimilation system. Quart. J. Roy. Meteor. Soc., 137, 553-597, https://doi.org/ 10.1002/qj.828.

Donner, R. V., R. Ehrcke, S. M. Barbosa, J. Wagner, J. F. Donges, and J. Kurths, 2012: Spatial patterns of linear and nonparametric long-term trends in Baltic sea-level variability. Nonlinear Processes Geophys., 19, 95-111, https://doi.org/ 10.5194/npg-19-95-2012.

Döscher, R., U. Willén, C. Jones, A. Rutgersson, H. E. M. Meier, U. Hansson, and L. P. Graham, 2002: The development of the coupled regional ocean-atmosphere model RCAO. Boreal Environ. Res., 7, 183-192, http://www.borenv.net/BER/pdfs/ ber7/ber7-183.pdf.

Egbert, G. D., S. Y. Erofeeva, and R. D. Ray, 2010: Assimilation of altimetry data for nonlinear shallow-water tides: Quarterdiurnal tides of the Northwest European Shelf. Cont. Shelf Res., 30, 668-679, https://doi.org/10.1016/j.csr.2009.10.011.

Ekman, M., 1988: The world's longest continued series of sea level observations. Pure Appl. Geophys., 127, 73-77, https://doi.org/ 10.1007/BF00878691.

- 1996: A consistent map of the postglacial uplift of Fennoscandia. Terra Nova, 8, 158-165, https://doi.org/10.1111/j.13653121.1996.tb00739.x

Fennel, W., H. Radtke, M. Schmidt, and T. Neumann, 2010: Transient upwelling in the central Baltic Sea. Cont. Shelf Res., 30, 2015-2026, https://doi.org/10.1016/j.csr.2010.10.002.

Feser, F., M. Barcikowska, O. Krueger, F. Schenk, R. Weisse, and L. Xia, 2015: Storminess over the North Atlantic and northwestern Europe-A review. Quart. J. Roy. Meteor. Soc., 141, 350-382, https://doi.org/10.1002/qj.2364.

Franck, H., W. Matthäus, and R. Sammler, 1987: Major inflows of saline water into the Baltic Sea during the present century. Gerlands Beitr. Geophys., 96, 517-531.
Franzke, C., 2012: Nonlinear trends, long-range dependence, and climate noise properties of surface temperature. J. Climate, 25, 4172-4183, https://doi.org/10.1175/JCLI-D-11-00293.1.

_ 2013: A novel method to test for significant trends in extreme values in serially dependent time series. Geophys. Res. Lett., 40, 1391-1395, https://doi.org/10.1002/grl.50301.

Frederikse, T., R. Riva, M. Kleinherenbrink, Y. Wada, M. van den Broeke, and B. Marzeion, 2016: Closing the sea level budget on a regional scale: Trends and variability on the northwestern European continental shelf. Geophys. Res. Lett., 43, 10864 10 872, https://doi.org/10.1002/2016GL070750.

Fu, W., J. She, and M. Dobrynin, 2012: A 20-year reanalysis experiment in the Baltic Sea using three-dimensional variational (3DVAR) method. Ocean Sci., 8, 827-844, https://doi.org/ 10.5194/os-8-827-2012.

Geyer, B., 2014: High-resolution atmospheric reconstruction for Europe 1948-2012: coastDat2. Earth Syst. Sci. Data, 6, 147164, https://doi.org/10.5194/essd-6-147-2014.

Gräwe, U., P. Holtermann, K. Klingbeil, and H. Burchard, 2015: Advantages of vertically adaptive coordinates in numerical models of stratified shelf seas. Ocean Modell., 92, 56-68, https://doi.org/10.1016/j.ocemod.2015.05.008.

Gustafsson, B. G., 2001: Quantification of water, salt, oxygen and nutrient exchange of the Baltic Sea from observations in the Arkona Basin. Cont. Shelf Res., 21, 1485-1500, https://doi.org/ 10.1016/S0278-4343(01)00014-0.

Haapala, J. J., I. Ronkainen, N. Schmelzer, and M. Sztobryn, 2015: Recent change-Sea ice. Second Assessment of Climate Change for the Baltic Sea Basin, Springer, 145-153, https:// doi.org/10.1007/978-3-319-16006-1.

Hay, C. C., E. Morrow, R. E. Kopp, and J. X. Mitrovica, 2015: Probabilistic reanalysis of twentieth-century sea-level rise. Nature, 517, 481-484, https://doi.org/10.1038/nature14093.

HELCOM, 1986: Water Balance of the Baltic Sea: 16th Baltic Sea Environment Proceedings, Baltic Marine Environment Protection Commission, http://www.helcom.fi/helcom-at-work/ publications/baltic-sea-environment-proceedings/.

Hofmeister, R., H. Burchard, and J.-M. Beckers, 2010: Non-uniform adaptive vertical grids for 3D numerical ocean models. Ocean Modell., 33, 70-86, https://doi.org/10.1016/j.ocemod.2009.12.003.

Holgate, S. J., and Coauthors, 2013: New data systems and products at the Permanent Service for Mean Sea Level. J. Coast. Res., 288 , 493-504. https://doi.org/10.2112/JCOASTRES-D-12-00175.1.

Holtermann, P., H. Burchard, U. Gräwe, K. Klingbeil, and L. Umlauf, 2014: Deep-water dynamics and boundary mixing in a nontidal stratified basin: A modeling study of the Baltic Sea. J. Geophys. Res. Oceans, 119, 1465-1487, https://doi.org/ 10.1002/2013JC009483.

Hünicke, B., and E. Zorita, 2008: Trends in the amplitude of Baltic Sea level annual cycle. Tellus, 60A, 154-164, https://doi.org/ 10.1111/j.1600-0870.2007.00277.x.

— , and 2016: Statistical analysis of the acceleration of Baltic mean sea-level rise, 1900-2012. Front. Mar. Sci., 3, 125, https://doi.org/10.3389/fmars.2016.00125.

Jevrejeva, S., and Coauthors, 2004: Baltic Sea ice seasons in the twentieth century. Climate Res., 25, 217-227, https://doi.org/ $10.3354 / \mathrm{cr} 025217$.

_ J. Moore, P. Woodworth, and A. Grinsted, 2005: Influence of large-scale atmospheric circulation on European sea level: Results based on the wavelet transform method. Tellus, 57A, 183-193, https://doi.org/10.3402/tellusa.v57i2.14609.

, — - A. Grinsted, A. Matthews, and G. Spada, 2014: Trends and acceleration in global and regional sea levels since 1807. 
Global Planet. Change, 113, 11-22, https://doi.org/10.1016/ j.gloplacha.2013.12.004.

Kalnay, E., and Coauthors, 1996: The NCEP/NCAR 40-Year Reanalysis Project. Bull. Amer. Meteor. Soc., 77, 437-471, https://doi.org/10.1175/1520-0477(1996)077<0437: TNYRP $>2.0 . C O ; 2$.

Karabil, S., E. Zorita, and B. Hünicke, 2018: Contribution of atmospheric circulation to recent off-shore sea-level variations in the Baltic Sea and the North Sea. Earth Syst. Dyn., 9, 69-90, https://doi.org/10.5194/esd-9-69-2018.

Kauker, F., and H. E. M. Meier, 2003: Modeling decadal variability of the Baltic Sea: 1. Reconstructing atmospheric surface data for the period 1902-1998. J. Geophys. Res., 108, 3267, https:// doi.org/10.1029/2003JC001797.

Klingbeil, K., and H. Burchard, 2013: Implementation of a direct nonhydrostatic pressure gradient discretisation into a layered ocean model. Ocean Modell., 65, 64-77, https://doi.org/ 10.1016/j.ocemod.2013.02.002.

_- M. Mohammadi-Aragh, U. Gräwe, and H. Burchard, 2014: Quantification of spurious dissipation and mixing-Discrete variance decay in a finite-volume framework. Ocean Modell., 81, 49-64, https://doi.org/10.1016/j.ocemod.2014.06.001.

_ F. Lemarié, L. Debreu, and H. Burchard, 2018: The numerics of hydrostatic structured-grid coastal ocean models: State of the art and future perspectives. Ocean Modell., 125, 80-105, https://doi.org/10.1016/j.ocemod.2018.01.007.

Köhl, A., 2015: Evaluation of the GECCO2 ocean synthesis: Transports of volume, heat and freshwater in the Atlantic. Quart. J. Roy. Meteor. Soc., 141, 166-181, https://doi.org/ 10.1002/qj.2347.

Lehmann, A., K. Getzlaff, and J. Harlaß, 2011: Detailed assessment of climate variability in the Baltic Sea area for the period 1958 to 2009. Climate Res., 46, 185-196, https://doi.org/ 10.3354/cr00876.

—, K. Höflich, P. Post, and K. Myrberg, 2017: Pathways of deep cyclones associated with large volume changes (LVCs) and major Baltic inflows (MBIs). J. Mar. Syst., 167, 11-18, https:// doi.org/10.1016/j.jmarsys.2016.10.014.

Liu, Y., H. E. M. Meier, and L. B. Axell, 2013: Reanalyzing temperature and salinity on decadal time scales using the ensemble optimal interpolation data assimilation method and a 3D ocean circulation model of the Baltic Sea. J. Geophys. Res. Oceans, 118, 5536-5554, https://doi.org/10.1002/jgrc.20384.

Luhamaa, A., K. Kimmel, A. Männik, and R. Room, 2011: High resolution re-analysis for the Baltic Sea region during 19652005 period. Climate Dyn., 36, 727-738, https://doi.org/ 10.1007/s00382-010-0842-y.

Madsen, K. S., J. L. Høyer, W. Fu, and C. Donlon, 2015: Blending of satellite and tide gauge sea level observations and its assimilation in a storm surge model of the North Sea and Baltic Sea. J. Geophys. Res. Oceans, 120, 6405-6418, https://doi.org/ 10.1002/2015JC011070.

Marcos, M., and M. N. Tsimplis, 2007: Forcing of coastal sea level rise patterns in the North Atlantic and the Mediterranean Sea. Geophys. Res. Lett., 34, L18604, https://doi.org/10.1029/ 2007GL030641.

Matthäus, W., and H. Franck, 1992: Characteristics of major Baltic inflows-A statistical analysis. Cont. Shelf Res., 12, 1375-1400, https://doi.org/10.1016/0278-4343(92)90060-W.

Meier, H. E. M., and F. Kauker, 2003: Modeling decadal variability of the Baltic Sea: 2. Role of freshwater inflow and large-scale atmospheric circulation for salinity. J. Geophys. Res., 108, 3368, https://doi.org/10.1029/2003JC001799.
Mitrovica, J. X., M. E. Tamisiea, J. L. Davis, and G. A. Milne, 2001: Recent mass balance of polar ice sheets inferred from patterns of global sea-level change. Nature, 409, 1026-1029, https:// doi.org/10.1038/35059054.

Omstedt, A., C. Pettersen, J. Rodhe, and P. Winsor, 2004: Baltic Sea climate: $200 \mathrm{yr}$ of data on air temperature, sea level variation, ice cover, and atmospheric circulation. Climate Res., 25, 205-216, https://doi.org/10.3354/cr025205.

Pätsch, J., and Coauthors, 2017: An evaluation of the North Sea circulation in global and regional models relevant for ecosystem simulations. Ocean Modell., 116, 70-95, https://doi.org/ 10.1016/j.ocemod.2017.06.005.

Peltier, W. R., 2004: Global glacial isostasy and the surface of the ice-age Earth: The ICE-5G (VM2) model and GRACE. Annu. Rev. Earth Planet. Sci., 32, 111-149, https://doi.org/ 10.1146/annurev.earth.32.082503.144359.

— D. F. Argus, and R. Drummond, 2015: Space geodesy constrains ice age terminal deglaciation: The global ICE-6G_C (VM5a) model. J. Geophys. Res. Solid Earth, 120, 450-487, https://doi.org/10.1002/2014JB011176.

Piecuch, C. G., S. Dangendorf, R. M. Ponte, and M. Marcos, 2016: Annual sea level changes on the North American northeast coast: Influence of local winds and barotropic motions. J. Climate, 29, 4801-4816, https://doi.org/10.1175/JCLI-D-16-0048.1.

Placke, M., H. E. M. Meier, U. Gräwe, T. Neumann, C. Frauen, and Y. Liu, 2018: Long-term mean circulation of the Baltic Sea as represented by various ocean circulation models. Front. Mar. Sci., 5, 287, https://doi.org/10.3389/fmars.2018.00287.

Reißmann, J. H., and Coauthors, 2009: Vertical mixing in the Baltic Sea and consequences for eutrophication-A review. Prog. Oceanogr., 82, 47-80, https://doi.org/10.1016/j.pocean.2007.10.004.

Reynolds, R. W., T. M. Smith, C. Liu, D. B. Chelton, K. S. Casey, and M. G. Schlax, 2007: Daily high-resolution-blended analyses for sea surface temperature. J. Climate, 20, 5473-5496, https://doi.org/10.1175/2007JCLI1824.1.

Ridal, M., E. Olsson, P. Unden, K. Zimmermann, and A. Ohlsson, 2017: Deliverable D2.7: HARMONIE reanalysis report of results and dataset. SMHI Tech. Rep., 22 pp., www.uerra.eu/component/ dpattachments/?task =attachment.download\&id $=297$.

Riva, R. E. M., T. Frederikse, M. A. King, B. Marzeion, and M. R. van den Broeke, 2017: Brief communication: The global signature of post-1900 land ice wastage on vertical land motion. Cryosphere, 11, 1327-1332, https://doi.org/10.5194/tc-111327-2017.

Rutgersson, A., and Coauthors, 2015: Recent change-Atmosphere. Second Assessment of Climate Change for the Baltic Sea Basin, Springer, 67-97, https://doi.org/10.1007/978-3-31916006-1.

Saha, S., and Coauthors, 2010: The NCEP Climate Forecast System Reanalysis. Bull. Amer. Meteor. Soc., 91, 1015-1057, https:// doi.org/10.1175/2010BAMS3001.1.

Schinke, H., and W. Matthäus, 1998: On the causes of major Baltic inflows-An analysis of long time series. Cont. Shelf Res., 18, 67-97, https://doi.org/10.1016/S0278-4343(97)00071-X.

Schreiber, T., and A. Schmitz, 1996: Improved surrogate data for nonlinearity tests. Phys. Rev. Lett., 77, 635-638, https://doi.org/ 10.1103/PhysRevLett.77.635.

Seifert, T., W. Fennel, and C. Kuhrts, 2009: High resolution model studies of transport of sedimentary material in the southwestern Baltic. J. Mar. Syst., 75, 382-396, https://doi.org/ 10.1016/j.jmarsys.2007.01.017.

Steffen, H., V. Barletta, K. Kollo, G. Milne, M. Nordmann, and P.-A. Olsson, 2014: NKG201xGIA-A model of glacial isostatic 
adjustment for Fennoscandia. Proc. 2014 NKG General Assembly, Göteborg, Sweden, Nordic Geodetic Commission, 85-86.

Stramska, M., and J. Białogrodzka, 2015: Spatial and temporal variability of sea surface temperature in the Baltic Sea based on 32-years (1982-2013) of satellite data. Oceanologia, 57, 223-235, https://doi.org/10.1016/j.oceano.2015.04.004.

Stryhal, J., and R. Huth, 2017: Classifications of winter EuroAtlantic circulation patterns: An intercomparison of five atmospheric reanalyses. J. Climate, 30, 7847-7861, https://doi.org/ 10.1175/JCLI-D-17-0059.1.

Suursaar, Ü., and J. Sooäär, 2007: Decadal variations in mean and extreme sea level values along the Estonian coast of the Baltic Sea. Tellus, 59A, 249-260, https://doi.org/10.1111/j.16000870.2006.00220.x.

Taylor, K. E., 2001: Summarizing multiple aspects of model performance in a single diagram. J. Geophys. Res., 106, 71837192, https://doi.org/10.1029/2000JD900719.

Theiler, J., S. Eubank, A. Longtin, B. Galdrikian, and J. Doyne Farmer, 1992: Testing for nonlinearity in time series: The method of surrogate data. Physica $D, \mathbf{5 8}, 77-94$, https://doi.org/ 10.1016/0167-2789(92)90102-S.

Umlauf, L., and H. Burchard, 2005: Second-order turbulence closure models for geophysical boundary layers. A review of recent work. Cont. Shelf Res., 25, 795-827, https://doi.org/ 10.1016/j.csr.2004.08.004.

Uppala, S. M., and Coauthors, 2005: The ERA-40 Re-Analysis. Quart. J. Roy. Meteor. Soc., 131, 2961-3012, https://doi.org/ 10.1256/qj.04.176.

van den Besselaar, E. J. M., A. M. G. Klein Tank, and T. A. Buishand, 2012: Trends in European precipitation extremes over 1951-2010. Int. J. Climatol., 33, 2682-2689, https://doi.org/ 10.1002/joc.3619.

Vestøl, O., J. Ågren, T. Oja, T. Kall, I. Liepins, E. Paršeliūnas, and A. Rüdja, 2014: NKG2014LU_test-A new empirical land uplift model over Fennoscandia. Proc. 2014 NKG General Assembly, Göteborg, Sweden, Nordic Geodetic Commission, 78-79, https://www.etis.ee/Portal/Publications/Display/f9c9896efefe-46da-8f64-e7d0fc4456e4. von Storch, H., H. Langenberg, and F. Feser, 2000: A spectral nudging technique for dynamical downscaling purposes. Mon. Wea. Rev., 128, 3664-3673, https://doi.org/10.1175/15200493(2000)128<3664:ASNTFD > 2.0.CO;2.

Wahl, T., and Coauthors, 2013: Observed mean sea level changes around the North Sea coastline from 1800 to present. Earth Sci. Rev., 124, 51-67, https://doi.org/10.1016/j.earscirev.2013.05.003.

Wakelin, S. L., P. L. Woodworth, R. A. Flather, and J. A. Williams, 2003: Sea-level dependence on the NAO over the NW European continental shelf. Geophys. Res. Lett., 30, 1403, https:/ doi.org/10.1029/2003GL017041.

Weisse, R., and H. Weidemann, 2017: Baltic Sea extreme sea levels 1948-2011: Contributions from atmospheric forcing. Procedia IUTAM, 25, 65-69, https://doi.org/10.1016/j.piutam. 2017.09.010.

— H. von Storch, and F. Feser, 2005: Northeast Atlantic and North Sea storminess as simulated by a regional climate model during 1958-2001 and comparison with observations. J. Climate, 18, 465-479, https://doi.org/10.1175/JCLI-3281.1.

— analyses and climate change projections: Results for northern Europe and potential for coastal and offshore applications. Bull. Amer. Meteor. Soc., 90, 849-860, https://doi.org/10.1175/ 2008BAMS2713.1.

Winton, M., 2000: A reformulated three-layer sea ice model. J. Atmos. Oceanic Technol., 17, 525-531, https://doi.org/ 10.1175/1520-0426(2000)017<0525:ARTLSI >2.0.CO;2.

Woodworth, P. L., F. N. Teferle, R. M. Bingley, I. Shennan, and S. D. P. Williams, 2009: Trends in UK mean sea level revisited. Geophys. J. Int., 176, 19-30, https://doi.org/10.1111/ j.1365-246X.2008.03942.x.

Yin, J., S. M. Griffies, and R. J. Stouffer, 2010: Spatial variability of sea level rise in twenty-first century projections. J. Climate, $\mathbf{2 3}$ 4585-4607, https://doi.org/10.1175/2010JCLI3533.1.

Zorita, E., and B. Hünicke, 2006: Influence of temperature and precipitation on decadal Baltic Sea level variations in the 20th century. Tellus, 58A, 141-153, https://doi.org/10.1111/j.16000870.2006.00157.x. 